\title{
High expression of EMP1 predicts a poor prognosis and correlates with immune infiltrates in bladder urothelial carcinoma
}

\author{
BO LIN, TIANWEN ZHANG, XIN YE and HONGYU YANG \\ Department of Oral and Maxillofacial Surgery, Peking University Shenzhen Hospital, \\ Shenzhen, Guangdong 518036, P.R. China
}

Received August 2, 2019; Accepted May 21, 2020

DOI: $10.3892 / \mathrm{ol} .2020 .11841$

\begin{abstract}
Epithelial membrane protein $1(E M P 1)$ is a key gene that regulates cell proliferation and metastatic capability in various types of cancer, and serves an important role in tumor-immune interactions. However, the association between EMPI and clinical prognosis, as well as the presence of tumor-infiltrating lymphocytes in bladder urothelial carcinoma (BLCA) remains unclear. The present study aimed to explore the relationship between EMPI expression and tumor immune cell infiltration in BLCA. In the present study, EMPI expression in BLCA was analyzed using the Oncomine database, The Cancer Genome Atlas (TCGA) and the Tumor Immune Estimation Resource (TIMER). The effects of EMPI on clinical prognosis were evaluated using the Kaplan-Meier plotter and Gene Expression Profiling Interactive Analysis. The correlations between EMPl, cancer immune infiltrates and lymphocyte abundance were determined using the TIMER and Tumor immune system interaction database. In addition, correlations between EMPl expression and gene markers in immune infiltrates were analyzed using cBioportal. The results demonstrated that, compared with adjacent normal tissues, EMPI was downregulated in BLCA tissues. High expression of EMPI was significantly associated with poor overall survival (OS) in BLCA cases obtained from TCGA. Multivariate Cox analysis revealed that EMPI was an independent predictor of OS in patients with BLCA. Gene set enrichment analysis revealed that EMPI was associated with cancer-related pathways and was positively correlated with the levels of infiltrating $\mathrm{CD}^{+} \mathrm{T}$ cells, macrophages, neutrophils and dendritic cells in BLCA. Further analysis demonstrated that EMPI was significantly associated with the enrichment of multiple types of lymphocyte. EMPI expression exhibited a strong correlation with a range of immune markers in BLCA. In conclusion, the results of the present study demonstrated that EMPI was associated with a poor prognosis in patients with BLCA, and that the levels of immune infiltration
\end{abstract}

Correspondence to: Dr Hongyu Yang, Department of Oral and Maxillofacial Surgery, Peking University Shenzhen Hospital, 1120 Lianhua Road, Futian, Shenzhen, Guangdong 518036, P.R. China E-mail: yanghongyu0520@163.com

Key words: epithelial membrane protein 1, immune infiltration, bladder urothelial carcinoma, expression, prognosis and multiple immunomarker groups were associated with EMP1 expression. These results suggested that EMPl may be used as a predictive biomarker to determine the prognosis and immune infiltration in BLCA.

\section{Introduction}

The incidence of bladder urothelial carcinoma (BLCA) ranks ninth among all malignancies in the global population and fourth among all malignancies occurring in men (1). The main risk factors of BLCA are cigarette smoking, exposure to toxic industrial chemicals and gases, and genetic susceptibility (2). Although standard treatment and supportive care have improved the overall survival (OS) and quality of life, the prognosis for patients with BLCA remains poor (3).

Immune-related mechanisms serve an important role in BLCA, and immunotherapeutic strategies are considered to be a promising direction for the treatment of $\operatorname{BLCA}(4,5)$. Immunotherapy seeks to manipulate the patient's own immune response to improve the clinical outcome by promoting immune cells that can kill target cancer cells (5). The receptor-ligand pairing of programmed cell death protein-1 (PD-1) has been identified to be a crucial immune checkpoint; however, current immunotherapies using anti-PD-1 have only achieved partial response in patients with advanced BLCA $(6,7)$. In addition, an increasing number of studies have demonstrated that patients with bladder cancer with a high level of tumor-infiltrating lymphocytes exhibit improved survival (8-10). However, studies on the prognostic value of immune cell subsets in patients with BLCA have yields completely opposite results (11). Therefore, there is an urgent need to elucidate the specific immune phenotypes of tumor-immune interactions and identify novel immune-associated therapeutic targets in BLCA.

Epithelial membrane protein $1(E M P l)$ is a protein-coding gene; its expression and significance in human cancer and its biological effects have been explored in vitro, demonstrating that EMP1 significantly reduces cell migration and invasion, and increases apoptosis and caspase- 9 expression in carcinoma of the nasopharynx, stomach, breast and prostate (12-16). By contrast, studies of acute lymphoblastic leukemia (ALL) have revealed that EMPl is an indicator of poor prognosis (17).

Limited information is available about the mechanism underlying the effects of EMP1. Previous studies have 
suggested that EMPI works primarily by regulating signal transduction between cells and the extracellular matrix (18). EMP1 may be associated with the proto-oncogene $c$-myc (19), and other studies have revealed that EMPl is regulated by the epidermal growth factor receptor (EGFR) $(20,21)$. In addition, EMPl is involved in the tight connection between cells, which may cause the occurrence and development of non-small cell lung cancer by activating the PI3K/AKT pathway (22). Wang et al (23), demonstrated that EMP family members and integrins synergistically regulate cell adhesion and migration in vitro, and integrin-based cell adhesion leads to autoimmune diseases. Therefore, previous studies have suggested that EMP1 serves an important role in tumorigenesis and tumor immunity, but the effects of this gene on the OS of patients with BLCA and the underlying function of EMPI in tumor-immune interactions remain unclear.

The present study aimed to comprehensively analyze EMP1 expression and its association with the prognosis of patients with BLCA. In addition, the correlation between EMP1 and tumor-infiltrating immune cells in the BLCA microenvironment was determined. The correlation between EMPI and the immune cell-specific genes reported in literature, as well as immunological checkpoint-specific genes were further studied, and the expression level of EMPI in tumor-tissue specimens and adjacent normal tissues of patients with BLCA were compared.

\section{Materials and methods}

Patients and tissue samples. Bladder cancer and adjacent normal tissues were collected from patients with BLCA at the Peking University Shenzhen Hospital (Shenzhen, China) between September 2018 and December 2019. The specimens were all collected during bladder cancer resection, and the distance between tumor tissue and adjacent normal tissue was $>2 \mathrm{~cm}$. BLCA was diagnosed and classified through pathological examination based on the World Health Organization classification system (24). Specimens from patients with a history of preoperative chemotherapy were excluded. The study protocol was approved by the Ethics Committees for Human Experiments of Peking University Shenzhen Hospital. All patients signed an informed consent form before sample collection.

Image processing. The paraffin-embedded tumor sections (5 $\mu \mathrm{m}$ thick) were stained with $\mathrm{H} \& \mathrm{E}$ or antibodies against EMP1 (cat. no. ab230445; 1:75; Abcam) according to the routine immunohistochemical staining method (25). All images shown are wide-field light microscopy images that were acquired at sufficient resolution.

Acquisition of mRNA data. The gene expression data and corresponding clinical information were downloaded from TCGA website (https://portal.gdc.cancer.gov) for BLCA, and estimated as $\log _{2}(x+1)$ transformed RSEM normalized counts (26). BLAC samples comprised samples of 404 patients with BCLA, including 28 cases with adjacent non-tumorous tissue as control group. All data were processed using R-studio software (v3.5.3) (27). The 'ESTIMATE' R package was used to predict the presence of infiltrating stromal/immune cells in tumor tissues using gene expression data (28).
Oncomine database analysis. The levels of EMPI gene expression in various types of cancer were identified using the Oncomine database (https://www. oncomine.org). The threshold was determined according to the following values: P-value of 0.001 and fold-change of 2 .

Kaplan-Meier plotter database analysis. The Kaplan Meier plotter (http://kmplot.com/analysis/) is capable of assessing the effect of 54,000 genes on patient survival in 21 types of cancer (29). The association between EMPI expression and survival in patients with BLCA was analyzed using the Kaplan-Meier plotter. The hazard ratio (HR) with $95 \%$ confidence intervals (CIs) and log-rank P-value were computed.

Tumor Immune Estimation Resource (TIMER) database analysis. TIMER (https://cistrome. shinyapps.io/timer/), which is a comprehensive resource for the systematic analysis of immune infiltrates across various types of cancer, was used in the present study to analyze the level of EMPI expression in BLCA and the correlation between EMPI expression and the abundance of immune infiltrates, including B cells, $\mathrm{CD} 4^{+} \mathrm{T}$ cells, $\mathrm{CD} 8^{+} \mathrm{T}$ cells, neutrophils, macrophages and dendritic cells via gene modules. The immune cell infiltration score of each patient in TCGA database was obtained using TIMER, and the patients were divided into high and low score groups based on the median value.

Immunological analysis by Tumor immune system interaction database (TISIDB). The correlations between the abundance of tumor-infiltrating lymphocytes and EMPI expression were analyzed using TISIDB (http://cis.hku.hk/TISIDB), which is a web portal for tumor and immune system interactions integrating multiple heterogeneous data types (30). In the present study, the enrichment data of 28 immune cells provided by TISIDB, including activated $\mathrm{CD}^{+}$cells (Act CD8), central memory CD8 cells (Tcm CD8), effector memory CD8 cells (Tem CD8), activated $\mathrm{CD}^{+}$cells (Act CD4), central memory CD4 cells (Tcm CD4), effector memory CD4 cells (Tem CD4), T follicular helper cells (Tfh), gamma delta $\mathrm{T}$ cells (Tgd), type $1 \mathrm{~T}$ helper cells (Th1), type $17 \mathrm{~T}$ helper cells (Th17), type $2 \mathrm{~T}$ helper cells (Th2), regulatory $\mathrm{T}$ cells (Treg), activated B cells (Act B), immature B cells (Imm B), memory B cells (Mem B), natural killer (NK) cells, CD56 bright NK cells (CD56bright), CD56 dim NK cells (CD56dim), myeloid derived suppressor cells (MDSCs), NK T cells (NKT), activated dendritic cell (Act DCs), plasmacytoid DCs (pDCs), immature DCs (iDCs), macrophages, eosinophils, mast cells (Mast), monocytes and neutrophils, were used to calculate the relationship with the expression of EMPl in BLCA.

Gene expression and survival analysis in Gene Expression Profiling Interactive Analysis (GEPIA). The online database GEPIA (http://gepia.cancer-pku.cn/index.html) was used to analyze the differential expression of EMPI and its prognostic values.

Co-expression analysis in cBioPortal. The cBioPortal for Cancer Genomics (https://www.cbioportal.org) is an open-access, open-source resource for interactive exploration of multidimensional cancer genomics datasets $(31,32)$ that was used in the present study to determine the correlations 
A

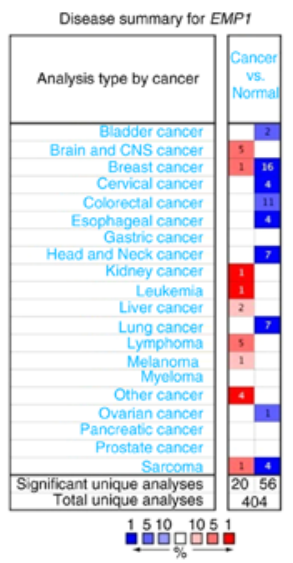

B

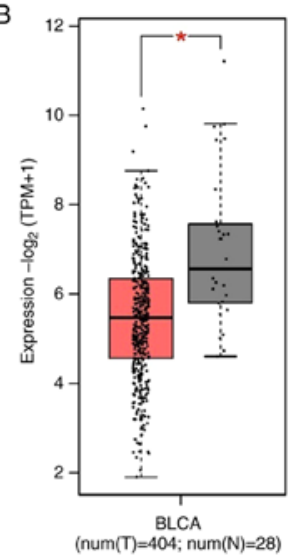

C

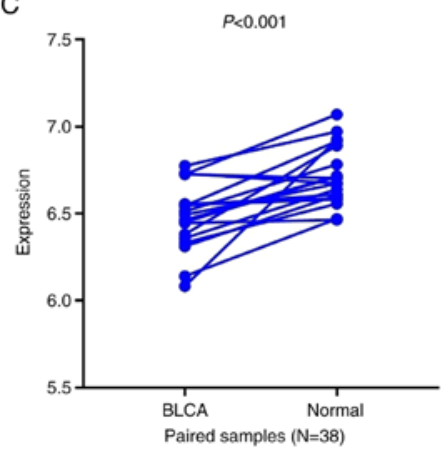

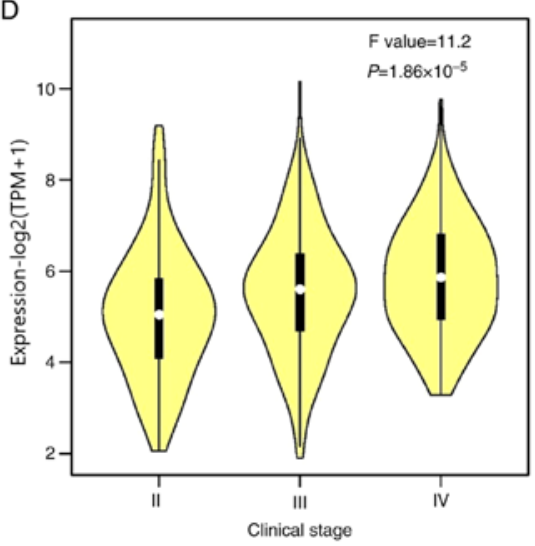

Figure 1. EMP1 expression levels in BLCA and other types of cancer. (A) EMP1 expression in datasets of various types of cancer in the Oncomine database. Cell color is determined by the best gene rank percentile for the analyses within the cell. Blue indicates upregulated EMP1 expression, and red indicates that the gene is downregulated. (B) EMP1 expression was compared between BLCA tissues and normal tissues from The Cancer Genome Atlas using Gene Expression Profiling Interactive Analysis. EMP1 expression in BLCA $(\mathrm{n}=404)$ was significantly lower compared with that in adjacent non-tumor tissues $(\mathrm{n}=28)$. (C) The level of EMP1 expression was compared between paired samples of BLCA and adjacent normal tissues of the same patient; EMP1 expression was significantly downregulated in BLCA compared with that in adjacent normal tissues. (D) The expression of EMP1 increases with clinical stage. The white dot in the center of the violin plot represents the median of EMP1 expression, and the black box represents the interquartile range. BLCA, bladder urothelial carcinoma; EMP1, epithelial membrane protein 1.

between $E M P 1$ expression and tumor-infiltrating immune cell markers. The gene markers of the tumor-infiltrating immune cells included markers of $\mathrm{CD}^{+} \mathrm{T}$ cells, $\mathrm{T}$ cells (general), B cells, monocytes, tumor associated macrophages (TAMs), M1 macrophages, M2 macrophages, neutrophils, NK cells, DCs, Th1 cells, Th 2 cells, follicular helper T (Tfh) cells, Th17 cells, Tregs and exhausted T cells. The Spearman rank correlation analysis was used to determine the correlation coefficient. EMPI expression was plotted on the x-axis, and the expression levels of other genes of interest were represented on the y-axis.

Gene set enrichment analysis (GSEA). To identify the potential mechanisms underlying the effects of EMPI expression on BLCA prognosis, GSEA was performed to detect whether an a priori defined set of genes exhibited statistically significant differential expression between the high and low EMP1 expression groups. Gene sets with a P-value $<0.05$ and false discovery rate $(\mathrm{FDR})<0.25$ in the enrichment of $\mathrm{MSigDB}$ Collection (c2.cp.kegg.v6.2. symbols) were considered to be significantly enriched.

Statistical analysis. Survival curves were generated using the GEPIA and Kaplan-Meier databases. $\mathrm{T}$ test and paired t test were implemented in prism and R software, and the results were displayed in the form of pictures and tables after sorting out the results. Receiver operating characteristic (ROC) curve and area under the curve (AUC) were used to demonstrate the predictive ability of EMP1 for 3- and 5-year OS. The results generated in Oncomine are presented as P-values, fold-changes and ranks. The results of the Kaplan-Meier plots and GEPIA are displayed with HR and P or Cox P-values from a log-rank test. Univariate Cox analysis was performed to select the potential prognostic factors, and multivariate Cox analysis was performed to verify the association between EMPl expression and survival along with other clinical features. $\mathrm{P}<0.05$ was considered to indicate a statistically significant difference.

\section{Results}

Association between EMPI expression and clinicopathologic variables in BLCA. As presented in Fig. 1A, EMP1 expression was upregulated in brain, breast, kidney and liver cancer, as well as in leukemia, lymphoma, melanoma and sarcoma compared with that in normal tissues. In addition, downregulation of EMPI was observed in bladder, breast, cervical, colorectal, esophageal, head and neck, lung, ovarian 
Table I. Logistic regression of the expression of EMP1 and the clinicopathological characteristics of patients with bladder urothelial carcinoma.

\begin{tabular}{lccc}
\hline Characteristic & Total & Odds ratio in EMP1 expression & P-value \\
\hline Age, years ( $\geq 60$ vs. $<60)$ & 407 & $1.64(1.02-2.67)$ & $0.04^{\mathrm{a}}$ \\
Subtype (papillary vs. non-papillary) & 402 & $0.65(0.42-0.98)$ & $0.04 \mathrm{a}$ \\
Sex (male vs. female) & 407 & $0.80(0.51-1.23)$ & 0.30 \\
Lymphovascular invasion (positive vs. negative) & 273 & $1.29(0.80-2.09)$ & 0.30 \\
Recurrence (yes vs. no) & 371 & $1.23(0.79-1.89)$ & 0.36 \\
Pathologic T classification (III-IV vs. I-II) & 374 & $1.80(1.17-2.81)$ & $8.4 \times 10^{-3 a}$ \\
Pathologic M classification (M+ vs. M0) & 200 & $0.90(0.59-1.38)$ & 0.21 \\
Pathologic N classification (N0 vs. N+) & 367 & $1.496(0.984-2.283)$ & 0.64 \\
Pathologic stage (III-IV vs. I-II) & 405 & $1.65(0.25-0.56)$ & 0.06 \\
Stromal score (high vs. low) & 408 & $1.54(0.29-0.64)$ \\
Immune score (high vs. low) & 408 & & $1.91 \times 10^{-6 a}$ \\
\hline
\end{tabular}

${ }^{\mathrm{a}} \mathrm{P}<0.05 .{ }^{\mathrm{b}} \mathrm{Grouped}$ according to the median value. EMP1, epithelial membrane protein 1.

cancer and sarcoma in a number of data sets. Differential expression was observed between tumor and normal tissues for $E M P 1$ in BLCA data from TCGA. The results indicated that EMPI was upregulated in BLCA compared with adjacent normal tissues $(\mathrm{P}<0.001$; Fig. $1 \mathrm{~B})$ and with paired adjacent healthy tissues $(\mathrm{P}<0.001$; Fig. $1 \mathrm{C})$. In addition, the expression of $E M P 1$ significantly increased with clinical stage $(\mathrm{P}<0.001$; Fig. 1D). The expression data of EMPI are presented in the supplementary materials (Table SI and Table SII).

Upregulation of EMP1 was significantly associated with advanced age ( $\geq 60$ vs. $<60, P=0.040)$, histological subtype (papillary vs. non-papillary, $\mathrm{P}=0.043$ ), pathologic $\mathrm{T}$ classification (III-IV vs. I-II, P=0.008), immune score (high vs. low, $\mathrm{P}<0.001$ ) and stromal score (high vs. low, $\mathrm{P}<0.001$; Table I). However, no significant associations between EMPI expression and sex, lymphovascular invasion, tumor recurrence, pathologic $\mathrm{M} / \mathrm{N}$ classification and pathologic stage were observed.

Survival outcomes and multivariate analysis. The analysis of BLCA cases in TCGA revealed that the 5-year OS of the high EMP1 expression group was significantly lower compared with that of the low expression group $(\mathrm{P}<0.001$; Fig. 2A). Receiver operating characteristic (ROC) curve analysis demonstrated the predictive ability of EMPI for 3- and 5-year OS with the area under the curve (AUC) of 0.737 and 0.739 , respectively (Fig. 2B). The association between EMP1 expression and survival outcome was further confirmed by Kaplan-Meier survival analysis (Fig. 2C). In addition, Fig. 2D-F demonstrated the relationship between EMPI and OS in stage II-IV patients. The results showed that $E M P 1$ overexpression was significantly associated with the poor prognosis of patients with stages II and IV.

The univariate analysis revealed that high EMPI expression was significantly associated with poor OS time (HR, 8.93; $95 \%$ CI, 3.71-21.47; $\mathrm{P}<0.001)$. Other clinicopathological characteristics associated with worse survival included age, pathologic stage, $\mathrm{CD}^{+} \mathrm{T}$ cell, macrophage infiltration, and stomal-score. In the multivariate analysis, EMP1 remained associated with poor OS (HR, 6.61; 95\% CI, 2.39-18.30; $\mathrm{P}<0.001)$ in conjunction with advanced age, pathologic stage, and macrophage infiltration (Table II). The data used for multivariate Cox regression are presented in the supplementary materials (Table SIII).

GSEA identifies an EMPl-related signaling pathway. The most significantly enriched signaling pathways were selected based on their normalized enrichment score. As demonstrated in Table III, pathways such as 'pathways in cancer', 'adherens junction', 'neurotrophin signaling pathway', 'endometrial cancer and focal adhesion' were differentially enriched in the high EMPl expression phenotype. These signaling pathways may be the mechanisms involved in EMPl function.

EMP1 expression is associated with the level of immune infiltration in BLCA. The level of EMPI expression correlated with high levels of immune infiltration in five types of immune cells and tumor purity in the TIMER dataset. EMP1 expression was significantly correlated with tumor purity and infiltration of $\mathrm{B}$ cells, $\mathrm{CD} 8^{+} \mathrm{T}$ cells, macrophages, neutrophils and DCs in BLCA as shown in Fig. 3. These results suggested that EMPI may serve a specific role in immune infiltration in BLCA. In addition, the survival analysis from TIMER dataset also showed that high levels of infiltrating $\mathrm{CD}^{+} \mathrm{T}$ cells were significantly associated with poor OS in patients with BLCA $(\mathrm{P}=0.006)$, and high expression of EMP1 predicted poor OS ( $\mathrm{P}<0.01$; Fig. 4).

Association between the abundance of tumor-infiltrating lymphocytes and EMPI expression. The results obtained from TISIDB demonstrated that EMPI expression was strongly associated with the abundance of Tcm CD8 and neutrophil cells (both correlation coefficients $>0.5$ and $\mathrm{P}<0.05$ ), and moderately related with the abundance of Mem B, Act CD4, Tcm CD4, Tem CD8, Act DC, pDC, iDC, NK, NKT, eosinophil, Tfh, Tgd, Th1, Th2, Treg, macrophage, mast and MDSC (all correlation coefficients between 0.3-0.5 and all $\mathrm{P}<0.05$ ) (Fig. 5).

Correlation between EMP1 expression and immune markers. The correlations between EMPI expression and immune 
A

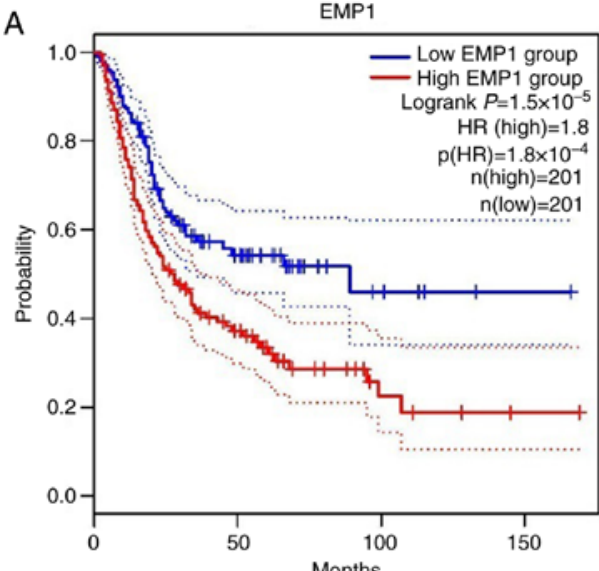

C

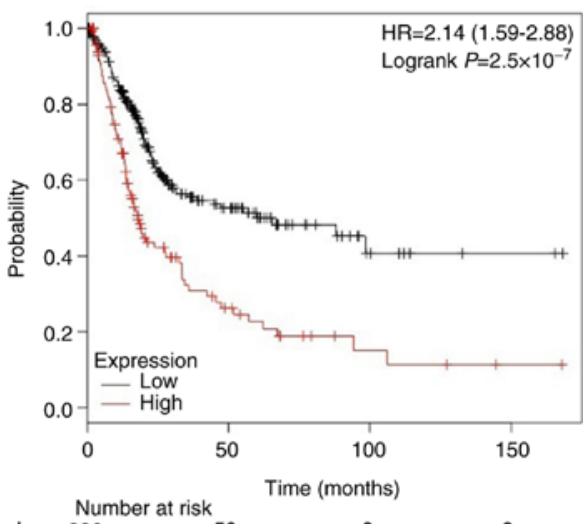

Now 286

High 118

E

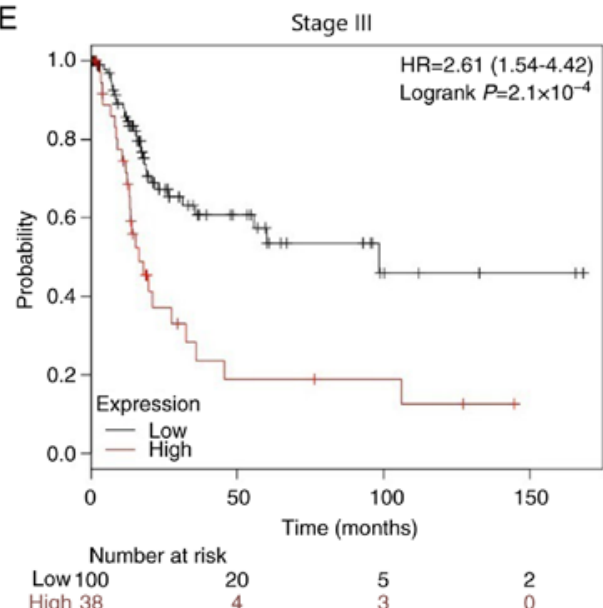

B

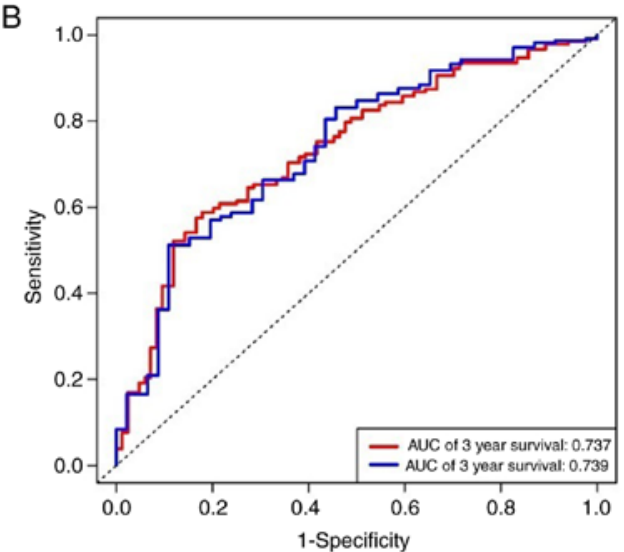

D

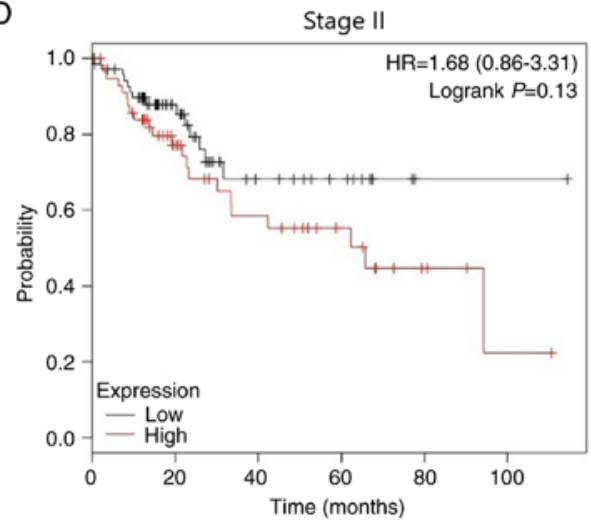

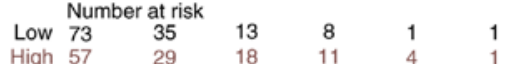

F Stage IV

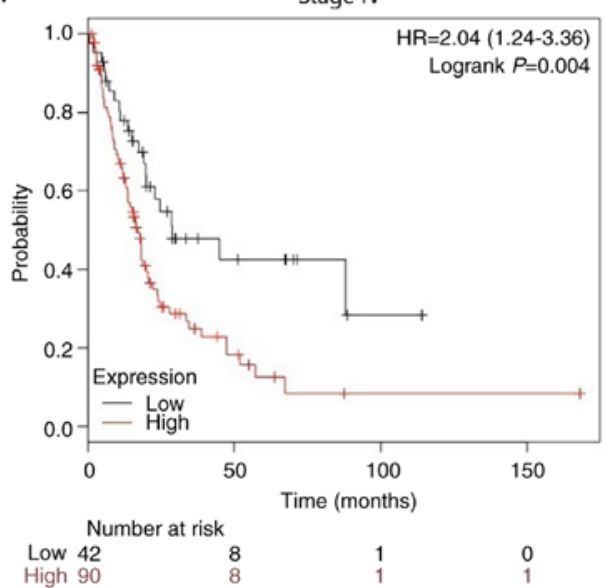

Figure 2. Association between EMP1 expression levels and the OS rate in patients with BLCA. (A) According to the median EMP1 expression level, patients with BLCA were divided into two groups with high and low expression, with 201 patients per group. High EMP1 expression predicted a poor OS rate based on The Cancer Genome Atlas data. (B) Receiver operating characteristic curve demonstrated the predictive ability of EMP1 in BLCA. (C) The OS results calculated by the Kaplan Meier plotter database; patients with low EMP1 expression group exhibited an improved OS rate. (D-F) Kaplan-Meier curves for OS in BLCA cases with clinical stages II-IV. The results demonstrated that the prognosis of the low EMP1 expression group was improved compared with that of the high expression group regardless of clinical stage. Moreover, there was a statistically significant difference in OS between the high and low expression groups in patients with tumors of clinical stages III and IV. BLCA, bladder urothelial carcinoma; EMP1, epithelial membrane protein 1; OS, overall survival; AUC, area under the curve.

marker genes of the different immune cells, including $\mathrm{CD}^{+} \mathrm{T}$ cells, T cells (general), B cells, monocytes, TAMs, M1 and M2 macrophages, neutrophils, NK cells and DCs are presented in Table IV. The results revealed that the level of EMPI expression was significantly correlated with immune markers of various immune cells. The expression levels of the majority of marker sets of monocytes, TAMs and M2 macrophages exhibited a significant correlation with EMPI expression. In particular, chemokine (C-C motif) ligand (CCL)-2, CD68, interleukin 10 (ILIO) of TAMs, prostaglandin-endoperoxide 
Table II. Univariate and multivariate analysis of overall survival using the Cox proportional hazard regression model $(\mathrm{N}=397)$.

\begin{tabular}{|c|c|c|c|c|c|c|}
\hline \multirow[b]{2}{*}{ Parameter } & \multicolumn{3}{|c|}{ Univariate analysis } & \multicolumn{3}{|c|}{ Multivariate analysis } \\
\hline & HR & $95 \% \mathrm{CI}$ & P-value & HR & $95 \% \mathrm{CI}$ & P-value \\
\hline Age & 1.033 & $1.017-1.049$ & $4.67 \times 10^{-5 a}$ & 1.029 & $1.012-1.046$ & $5.0 \times 10^{-4 a}$ \\
\hline Subtype $^{c}$ & 0.650 & $0.454-0.929$ & $0.018^{\mathrm{a}}$ & 0.814 & $0.558-1.187$ & 0.286 \\
\hline Sex & 0.880 & $0.633-1.224$ & 0.449 & 0.862 & $0.611-1.215$ & 0.395 \\
\hline Pathologic stage & 2.240 & $1.538-3.262$ & $2.6 \times 10^{-5 a}$ & 1.880 & $1.261-2.802$ & $0.002^{\mathrm{a}}$ \\
\hline B cell & 0.0741 & $0.007-0.754$ & 0.028 & 0.116 & $0.010-1.269$ & 0.078 \\
\hline $\mathrm{CD}^{+}{ }^{+} \mathrm{T}$ cell & 0.286 & $0.042-1.954$ & 0.202 & 1.415 & $0.047-42.416$ & 0.841 \\
\hline $\mathrm{CD}^{+} \mathrm{T}$ cell & 5.701 & $1.430-22.730$ & $0.014^{\mathrm{a}}$ & 5.243 & $0.407-67.569$ & 0.204 \\
\hline Neutrophil & 0.652 & $0.076-5.614$ & 0.697 & 0.006 & $0.000-0.737$ & $0.037^{\mathrm{a}}$ \\
\hline Macrophage & 18.825 & 4.514-78.518 & $5.62 \times 10^{-5 a}$ & 8.867 & $1.506-52.216$ & $0.016^{\mathrm{a}}$ \\
\hline Dendritic & 0.898 & $0.428-1.884$ & 0.776 & 1.350 & $0.300-6.039$ & 0.696 \\
\hline Stromal score ${ }^{b}$ & 0.728 & $0.530-0.973$ & $0.033^{\mathrm{a}}$ & 1.043 & $0.710-1.530$ & 0.832 \\
\hline Immune score ${ }^{b}$ & 1.072 & $0.795-1.446$ & 0.649 & 1.015 & $0.668-1.542$ & 0.944 \\
\hline EMP1 & 8.927 & $3.713-21.466$ & $1.01 \times 10^{-6 \mathrm{a}}$ & 6.614 & $2.390-18.301$ & $2.75 \times 10^{-4 a}$ \\
\hline
\end{tabular}

${ }^{\mathrm{a}} \mathrm{P}<0.05 .{ }^{\mathrm{b}} \mathrm{Grouped}$ according to the median value. ${ }^{\mathrm{c}}$ Papillary vs. non-papillary subtype. EMP1, epithelial membrane protein $1 ; \mathrm{HR}$, hazard ratio; CI, confidence interval.

Table III. Gene sets enriched analysis of upregulated EMP1 in BLCA.

\begin{tabular}{lcc}
\hline NAME & NES & P-value \\
\hline KEGG ECM RECEPTOR INTERACTION & 1.696 & 0.000 \\
KEGG FOCAL ADHESION & 1.795 & 0.000 \\
KEGG PATHWAYS IN CANCER & 1.592 & 0.002 \\
KEGG NEUROTROPHIN SIGNALING PATHWAY & 1.595 & 0.006 \\
KEGG AXON GUIDANCE & 1.612 & 0.008 \\
KEGG CELL ADHESION MOLECULES CAMS & 1.547 & 0.008 \\
KEGG GAP JUNCTION & 1.527 & 0.010 \\
KEGG ENDOMETRIAL CANCER & 1.625 & 0.017 \\
KEGG HEMATOPOIETIC CELL LINEAGE & 1.484 & 0.019 \\
KEGG NICOTINATE AND NICOTINAMIDE METABOLISM & 1.523 & 0.023 \\
KEGG ADHERENS JUNCTION & 1.753 & 0.024 \\
KEGG GLIOMA & 1.559 & 0.027 \\
KEGG RENAL CELL CARCINOMA & 1.530 & 0.046 \\
KEGG FC GAMMA R MEDIATED PHAGOCYTOSIS & 1.536 & 0.046 \\
\hline
\end{tabular}

Gene sets with $\mathrm{P}<0.05$ and false discovery rate $<0.25$ were considered significant. NES, normalized enrichment score. EMP1, epithelial membrane protein 1; BLCA, bladder urothelial carcinoma.

synthase 2 (PTGS2), interferon regulatory factor 5 (IRF5) of the M1 phenotype, $C D 163$, V-set and immunoglobulin domain containing 4 (VSIG4), and membrane spanning 4-domains A4A $(M S 4 A 4 A)$ of the M2 phenotype significantly correlated with EMP1 expression in BLCA $(\mathrm{P}<0.05)$, suggesting that EMP1 may regulate macrophage polarization. High EMPI expression is was associated with a high level of DC infiltration in BLCA; DC markers, such as Major Histocompatibility Complex, Class II, DP Beta 1 (HLA-DPB1) and Integrin Subunit Alpha X (ITGAX) also exhibited a significant correla- tion with EMP1 expression. In addition, for Tregs, a moderate positive correlation was observed between forkhead box P3 (FOXP3), C-C Motif Chemokine Receptor 8 (CCR8) and $E M P 1$ in BLCA. Therefore, these results further confirmed that $E M P 1$ was associated with infiltrating immune cells in BLCA, which suggested that EMPI may serve a crucial role in immune enhancement in the BLCA microenvironment.

EMP1 expression and immune checkpoint correlation analysis. The correlations between EMPI and the specific genes of the 


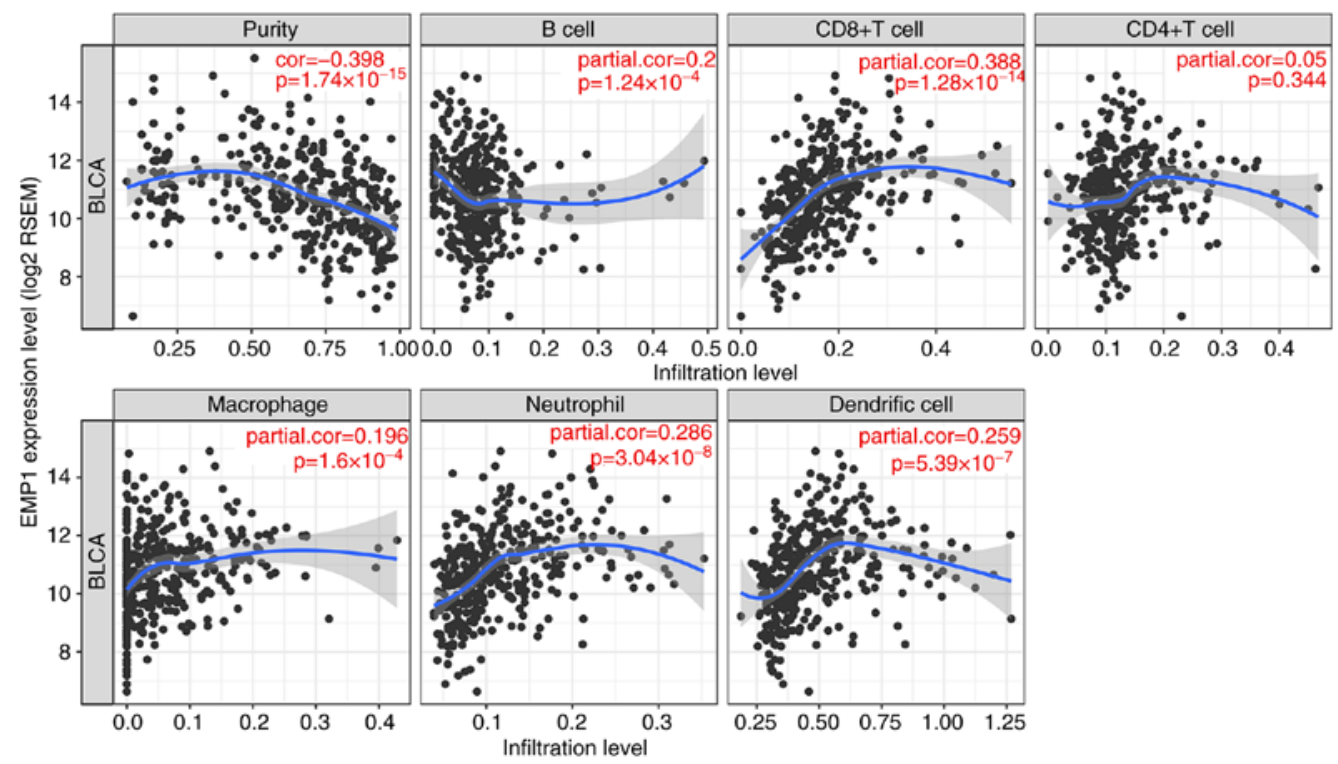

Figure 3. Correlations between EMP1 expression level and BLCA immune infiltration obtained from the Tumor Immune Estimation Resource database.
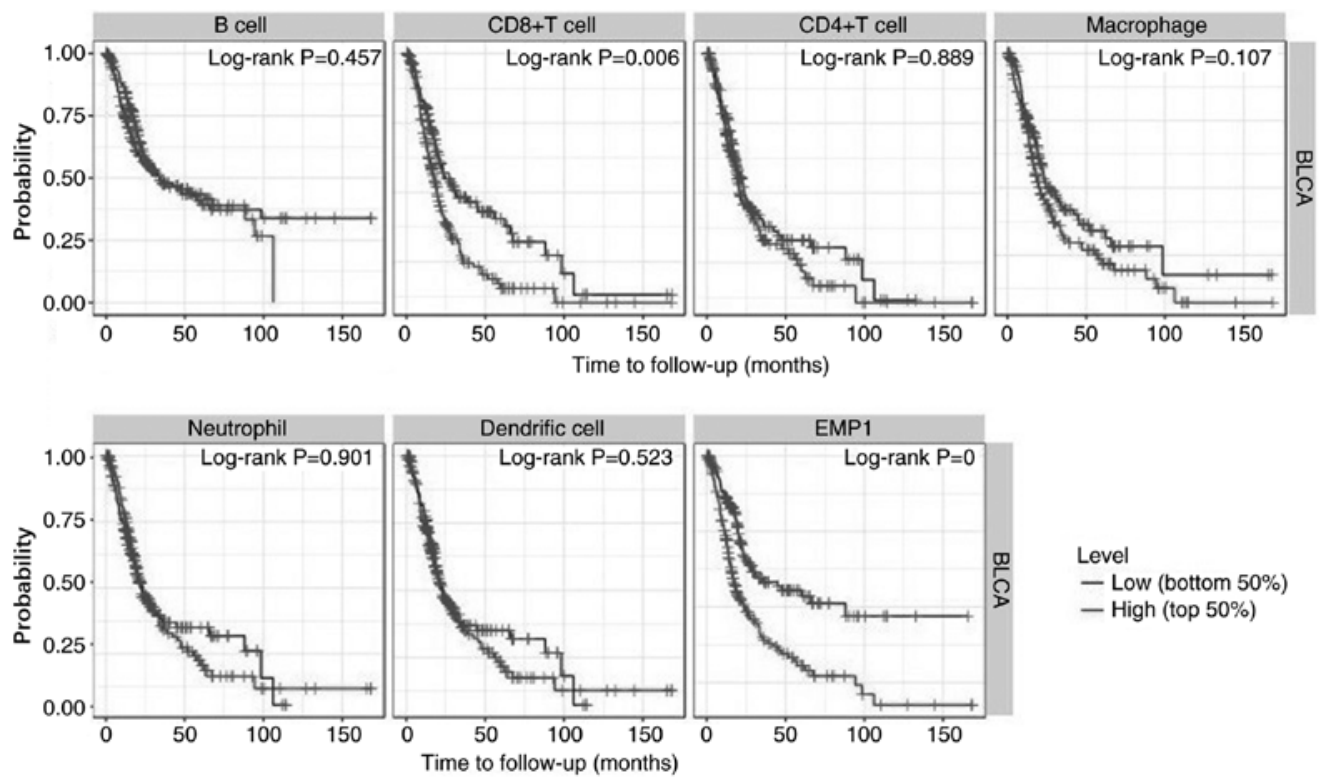

Figure 4. Effects of multiple tumor immune subsets and EMP1 on the prognosis of BLCA patients. The level of CD8 ${ }^{+}$cell infiltration as well as EMP1 expression were significantly associated with poor OS in all BLCA cases. However, there was no significant association between the infiltration of B cells, CD4 ${ }^{+} \mathrm{T}$ cells, macrophages, neutrophils or dendritic cells and OS. BLCA, bladder urothelial carcinoma; EMP1, epithelial membrane protein 1; OS, overall survival.

immune checkpoints that have been reported in the literature were further assessed. Programmed cell death 1 ligand 1 (CD274), programmed cell death 1 ligand 2 (PDCDILG2), hepatitis A virus cellular receptor 2 (HAVCR2), cytotoxic T-lymphocyte associated protein 4 (CTLA4), lymphocyte-activating 3 (LAG3), programmed cell death $1(P D C D I)$ and T cell immunoreceptor with Ig and ITIM domains (TIGIT) were selected for analysis as they have been previously reported to be immunological checkpoint-specific genes. EMP1 was significantly associated with the expression of these genes $(\mathrm{P}<0.05$; Fig. 6).

Expression of EMPI in BLCA specimens and adjacent normal tissue. Bladder cancer specimens from eight patients with pathologically confirmed BLCA were analyzed in the present study. The patients were all male, and the age range was 66-82 years. Immunohistochemical staining of BLCA tissue specimens and adjacent normal tissues revealed that EMP1 was strongly stained in adjacent normal tissues, but was the staining intensity was lower in tumor tissues (Fig. 7).

\section{Discussion}

The present study examined the levels of EMPI expression and the systematic prognostic landscape in BLCA using independent datasets in the Oncomine and TCGA databases. Differential levels of EMPI expression between cancer and normal tissues were observed. Consistent prognostic associations of EMPI expression in BLCA were identified, in 

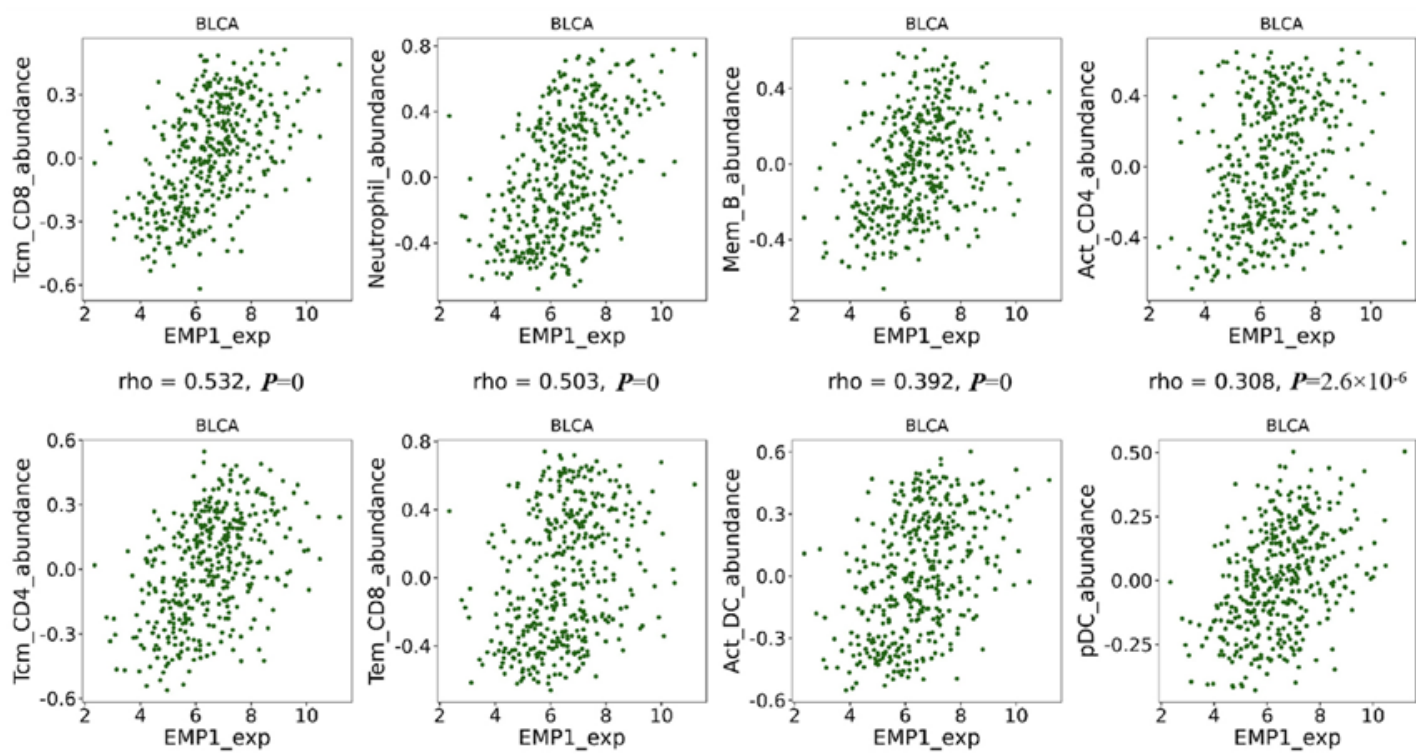

rho $=0.308, P=2.6 \times 10^{-6}$

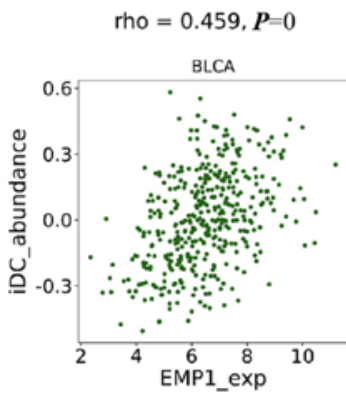

rho $=0.355, P=1.97 \times 10^{-13}$

rho $=0.438, P=0$
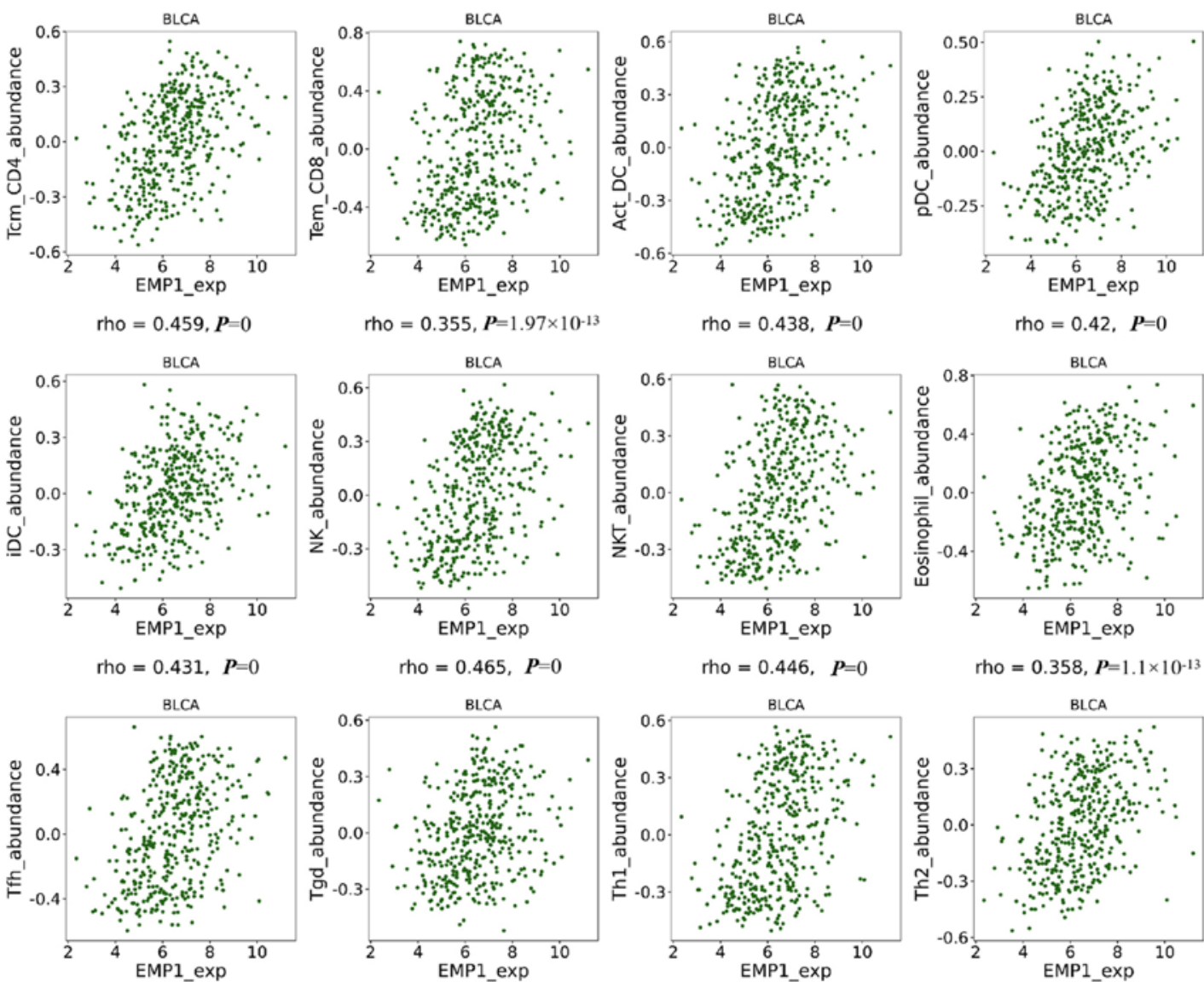

rho $=0.395, P=0$

rho $=0.304, P=4.4 \times 10^{-10}$

rho $=0.451, P=0$

rho $=0.416, \quad P=0$
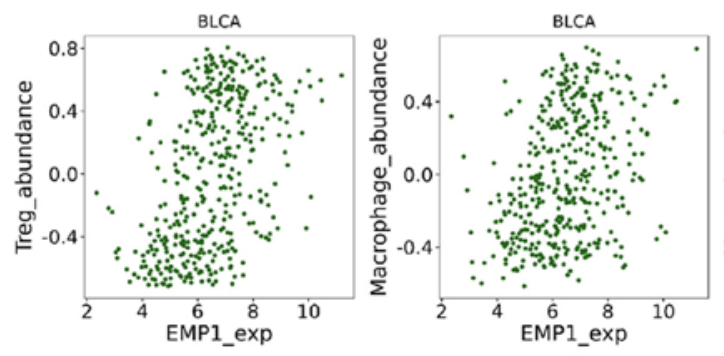

BLCA
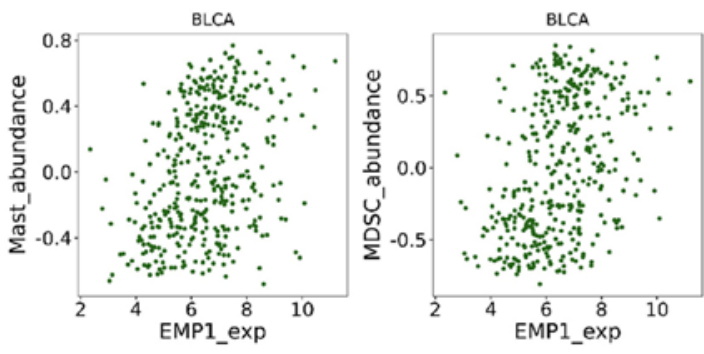

rho $=0.486, P=0$

rho $=0.367, P=2.18 \times 10^{-14}$

rho $=0.356, P=1.75 \times 10^{-13}$

rho $=0.392, P=0$

Figure 5. Correlations between EMP1 expression levels and lymphocyte abundance in BLCA using Tumor immune system interaction database. BLCA, bladder urothelial carcinoma; EMP1, epithelial membrane protein 1; Tcm CD8, central memory CD8 cells; Mem B, memory B cells; Act CD4, activated CD4 ${ }^{+}$cells; Tcm CD4, central memory CD4 cells; Tem CD8, effector memory CD8 cells; Act DCs, activated dendritic cell; pDCs, plasmacytoid DCs; iDCs, immature DCs; NK, natural killer cells; NKT, NK T cells; Tfh, T follicular helper cells; Tgd, gamma delta; Th1, type 1 T helper cells; Th2, type 2 T helper cells; Treg, regulatory T cells; MDSCs, myeloid derived suppressor cells; Mast, mast cells.

which high levels of EMPI expression were associated with a poor OS rate, and further analysis using the Kaplan-Meier plotter revealed that EMPI overexpression was associated with poor BLCA prognosis in stages III to IV. The results of the TIMER database analysis demonstrated significant positive correlations between the levels of EMPI expression and the infiltration of $\mathrm{CD}^{+} \mathrm{T}$ cells, macrophages, neutrophils and DCs in BLCA; however, EMPI expression was 
Table IV. Correlation analysis between EMP1 and the genes and markers of immune cells in cBioportal.

\begin{tabular}{|c|c|c|c|}
\hline Cell type & Gene & Spearman's correlation & P-value \\
\hline \multirow[t]{3}{*}{$\mathrm{CD}^{+} \mathrm{T}$ cell } & $C D 8 A$ & 0.214 & $1.30 \times 10^{-5 a}$ \\
\hline & $C D 8 B$ & 0.092 & 0.060 \\
\hline & $C D 80$ & 0.375 & $4.48 \times 10^{-15 a}$ \\
\hline \multirow[t]{3}{*}{$\mathrm{T}$ cell (general) } & $C D 3 D$ & 0.160 & $0.001^{\mathrm{a}}$ \\
\hline & $C D 3 E$ & 0.240 & $9.70 \times 10^{-7 a}$ \\
\hline & $C D 2$ & 0.207 & $2.42 \times 10^{-5 a}$ \\
\hline \multirow[t]{2}{*}{ B cell } & $C D 19$ & 0.104 & $0.036^{\mathrm{a}}$ \\
\hline & $C D 79 A$ & 0.177 & $3.26 \times 10^{-4 a}$ \\
\hline \multirow[t]{2}{*}{ Monocyte } & $C D 86$ & 0.434 & $3.88 \times 10^{-20 \mathrm{a}}$ \\
\hline & $C D 115$ & 0.417 & $4.11 \times 10^{-17 \mathrm{a}}$ \\
\hline \multirow[t]{3}{*}{ TAM } & CCL2 & 0.342 & $1.24 \times 10^{-12 \mathrm{a}}$ \\
\hline & CD68 & 0.366 & $2.38 \times 10^{-14 a}$ \\
\hline & IL10 & 0.394 & $1.25 \times 10^{-16 \mathrm{a}}$ \\
\hline \multirow[t]{3}{*}{ M1 Macrophage } & NOS2 & 0.131 & $0.008^{\mathrm{a}}$ \\
\hline & IRF5 & -0.199 & $5.37 \times 10^{-5 a}$ \\
\hline & PTGS2 & 0.296 & $1.10 \times 10^{-9 a}$ \\
\hline \multirow[t]{3}{*}{ M2 Macrophage } & $C D 163$ & 0.442 & $6.27 \times 10^{-21 a}$ \\
\hline & VSIG4 & 0.436 & $2.22 \times 10^{-20 \mathrm{a}}$ \\
\hline & $M S 4 A 4 A$ & 0.403 & $2.85 \times 10^{-18 a}$ \\
\hline \multirow[t]{2}{*}{ Neutrophil } & ITGAM & 0.381 & $1.51 \times 10^{-15 \mathrm{a}}$ \\
\hline & $C C R 7$ & -0.141 & $0.004^{\mathrm{a}}$ \\
\hline \multirow[t]{7}{*}{ Natural killer cell } & $K I R 2 D L 1$ & 0.200 & $4.87 \times 10^{-5 a}$ \\
\hline & $K I R 2 D L 3$ & 0.223 & $5.35 \times 10^{-6 a}$ \\
\hline & $K I R 2 D L 4$ & 0.268 & $3.92 \times 10^{-8 \mathrm{a}}$ \\
\hline & $K I R 3 D L 1$ & 0.141 & $0.004^{*}$ \\
\hline & $K I R 3 D L 2$ & 0.170 & $5.83 \times 10^{-4 a}$ \\
\hline & KIR3DL3 & 0.067 & 0.179 \\
\hline & KIR2DS4 & 0.149 & $0.003^{\mathrm{a}}$ \\
\hline \multirow[t]{7}{*}{ Dendritic cell } & $H L A-D P B 1$ & 0.279 & $9.81 \times 10^{-9 a}$ \\
\hline & $H L A-D Q B 1$ & 0.240 & $9.04 \times 10^{-7 \mathrm{a}}$ \\
\hline & $H L A-D R A$ & 0.270 & $3.06 \times 10^{-8 \mathrm{a}}$ \\
\hline & $H L A-D P A 1$ & 0.277 & $1.35 \times 10^{-8 \mathrm{a}}$ \\
\hline & $C D 1 C$ & 0.262 & $8.34 \times 10^{-8 a}$ \\
\hline & ITGAX & 0.392 & $1.99 \times 10^{-16 a}$ \\
\hline & $N R P 1$ & 0.455 & $3.15 \times 10^{-22 \mathrm{a}}$ \\
\hline \multirow[t]{5}{*}{ Th1 } & $T B X 21$ & 0.210 & $1.98 \times 10^{-5 a}$ \\
\hline & STAT4 & 0.364 & $2.94 \times 10^{-14 a}$ \\
\hline & STAT1 & 0.282 & $6.46 \times 10^{-9 a}$ \\
\hline & $I F N-g$ & 0.161 & $0.001^{\mathrm{a}}$ \\
\hline & $T N F-a$ & 0.153 & $0.002^{\mathrm{a}}$ \\
\hline \multirow[t]{3}{*}{ Th2 } & GATA3 & -0.497 & $7.77 \times 10^{-27 a}$ \\
\hline & STAT6 & -0.173 & $4.48 \times 10^{-4 a}$ \\
\hline & IL13 & 0.181 & $2.38 \times 10^{-4 a}$ \\
\hline \multirow[t]{2}{*}{ Tfh } & BCL6 & -0.144 & $0.004^{\mathrm{a}}$ \\
\hline & IL21 & 0.041 & 0.409 \\
\hline \multirow[t]{2}{*}{ Th17 } & STAT3 & 0.431 & $7.67 \times 10^{-20 \mathrm{a}}$ \\
\hline & $I L 17 A$ & -0.071 & 0.153 \\
\hline
\end{tabular}


Table IV. Continued.

\begin{tabular}{lccr}
\hline Cell type & Gene & Spearman's correlation & P-value \\
\hline Treg & $F O X P 3$ & 0.254 & $1.91 \times 10^{-7 \mathrm{a}}$ \\
& $C C R 8$ & 0.274 & $1.80 \times 10^{-8 \mathrm{a}}$ \\
& $T G F b$ & 0.314 & $8.82 \times 10^{-11 \mathrm{a}}$ \\
\hline
\end{tabular}

${ }^{\mathrm{a}} \mathrm{P}<0.05$. TAM, tumor-associated macrophage; Th, T helper cell; Tfh, follicular helper T cell; Treg, regulatory T cell; CSF1R, colony-stimulating factor 1 receptor; CCL2, C-C motif chemokine ligand 2; IL10, interleukin 10; INOS (NOS2), nitric oxide synthase 2; IRF5, interferon regulatory factor 5; PTGS2, prostaglandin-endoperoxide synthase 2; VSIG4, V-set and immunoglobulin domain-containing 4; MS4A4A, membrane-spanning 4 domains A4A; CEACAM8, carcinoembryonic antigen-related cell adhesion molecule 8; ITGAM, integrin subunit $\alpha$ M; CCR7, C-C motif chemokine receptor 7; KIR2DL1, killer cell immunoglobulin-like receptor, two Ig domains and long cytoplasmic tail 1; HLA-DPB1, major histocompatibility complex class II DP $\beta 1$; CD1C, CD1c molecule; ITGAX, integrin subunit $\alpha$; NRP1, neuropilin 1; TBX21, T-box 21; STAT4, signal transducer and activator of transcription 4; IFN-g, interferon $\gamma$; TNF- $\alpha$, tumor necrosis factor $\alpha$; GATA3, GATA-binding protein 3; BCL6, BCL6 transcription repressor; FOXP3, forkhead box P3; CCR8, C-C motif chemokine receptor 8; STAT5B, signal transducer and activator of transcription 5B; TGFB1, transforming growth factor $\beta 1$.

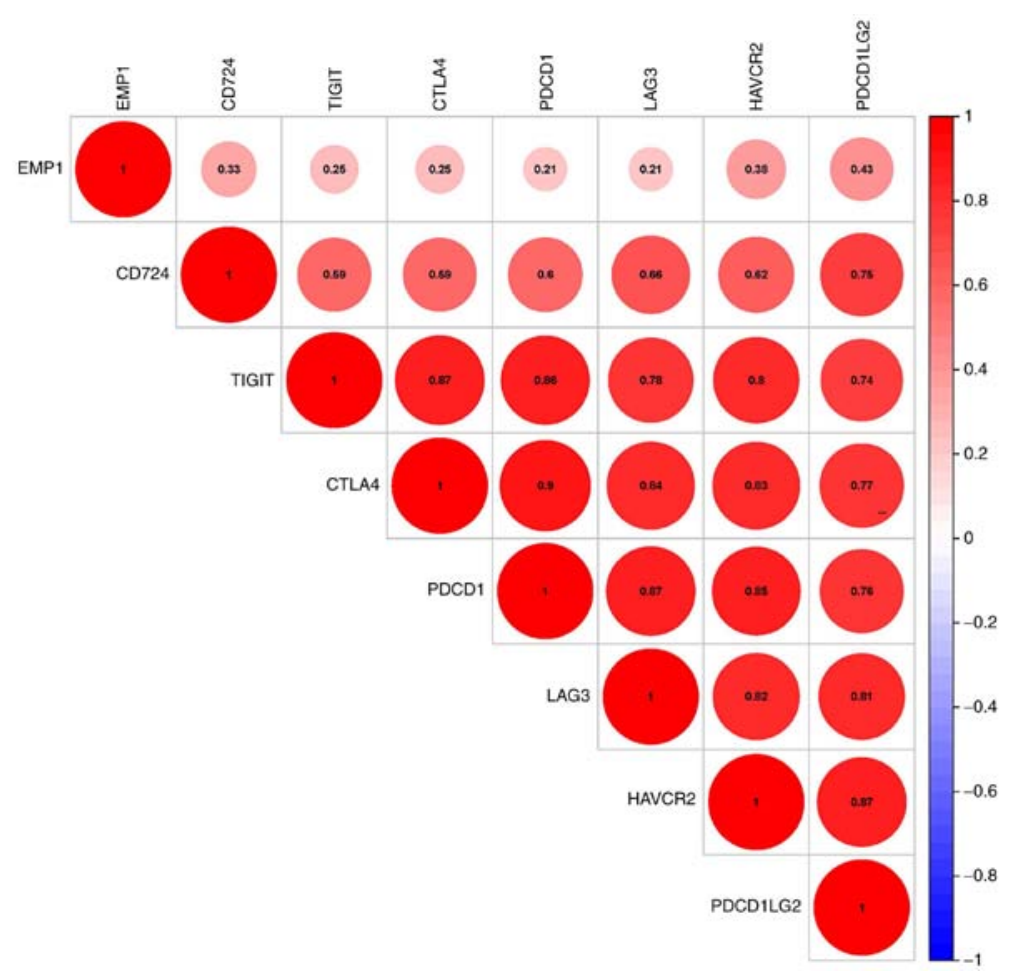

Figure 6. Correlations between EMP1 and immune checkpoint-related genes. Red represents a positive correlation, and blue represents a negative correlation. The size and color intensity of the circle indicates the strength of the correlation. The number in the circle indicates the correlation coefficient. BLCA, bladder urothelial carcinoma; EMP1, epithelial membrane protein 1.

negatively correlated with the infiltration of B cells, as well as the degree of tumor purity. Further analysis revealed that the upregulation of EMPI was significantly positively associated with an abundance of macrophages, but negatively associated with the levels of Tregs, plasma and CD4-naïve $\mathrm{T}$ cells. The co-expression analysis of EMPI and the previously reported immunolabeled genes also yielded consistent results. The expression level of EMPI in BLCA tissues was further validated using independent specimens. These results suggested that EMPI may be a prognostic biomarker, as well as an important factor for the recruitment and regulation of infiltrating immune cells in BLCA.
EMP1 was selected as the research object mainly based on the following considerations: Through the analysis of multiple databases, a significant difference was observed in the expression of EMPI between bladder cancer and paired normal tissues, and only one study suggested that EMPI was expressed at low levels in bladder cancer (33). However, it was necessary to further study this gene as its function in bladder cancer was not clear. EMPl belongs to the peripheral myelin protein 22 (PMP22) family and has high homology among the family members $(34,35)$. $P M P 22$ is considered to serve an important role in the immune response (36-38). Thus, it was speculated that EMP1 may exert a similar function. 


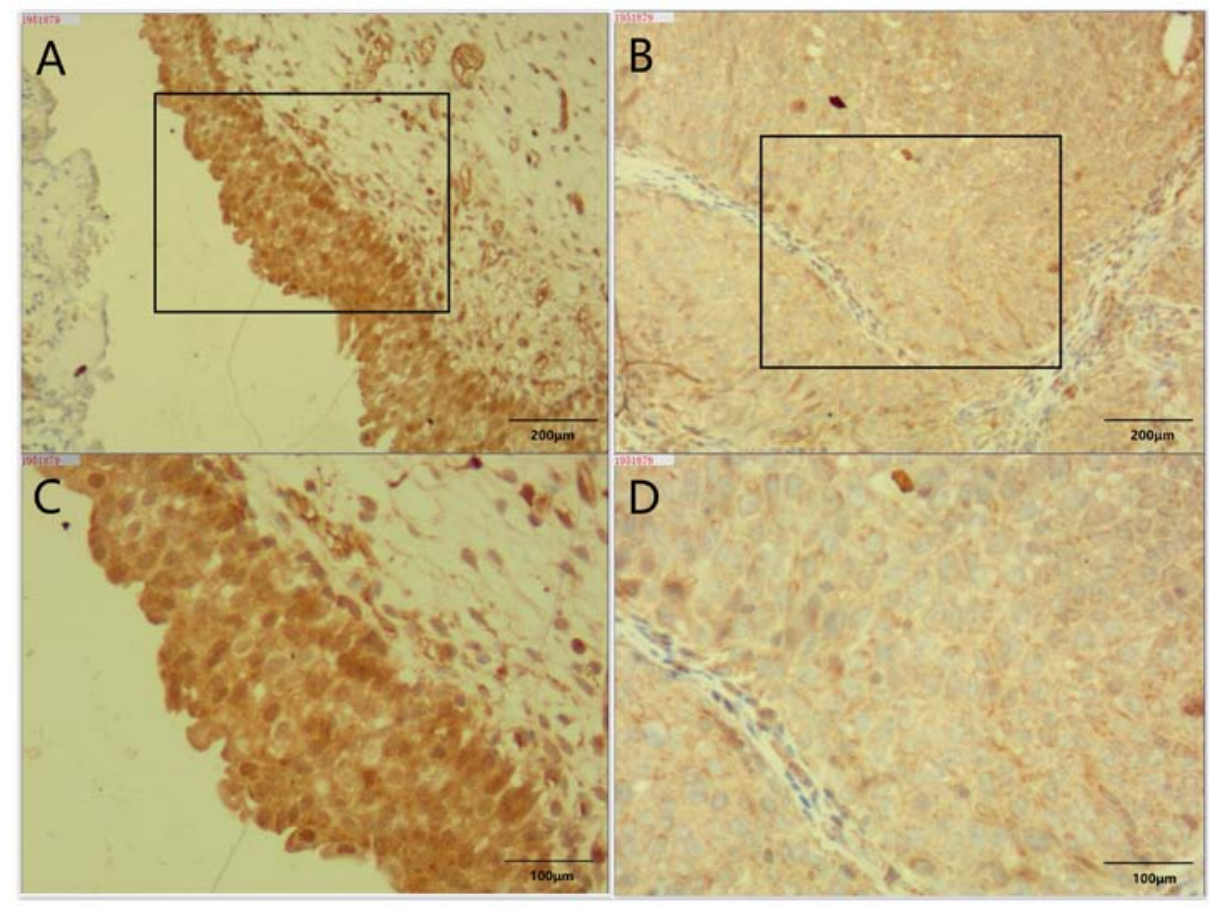

Figure 7. EMP1 is downregulated in BLCA. Immunohistochemical staining was performed to detecting the expression of EMP1 in (A and C) adjacent normal tissues and (B and D) tumor tissue specimens of patients with BLCA. (A and B) Magnification, x200. (C and D) Magnification, x400. BLCA, bladder urothelial carcinoma; EMP1, epithelial membrane protein 1.

Alteration of EMPI has been implicated in different types of human cancer. Cancer cell lines transfected with EMPI in vitro, including PC-3 prostate cancer, SW-480 colon cancer and MCF-7 breast cancer have been demonstrated to exhibit a high rate of apoptosis and a poor survival rate $(14,15)$. The EMP1 gene expression has also been demonstrated to be downregulated in laryngeal, esophageal, head and neck, sclerosing gastric and prostate cancer, as well as in uterine fibroids compared with that in normal tissues (39-43). Sun et al (12), have demonstrated that as a tumor suppressor gene, high expression of EMPI can improve the 5-year survival rate of patients with nasopharyngeal cancer. This result was also confirmed in gastric cancer (13), and EMP1 was reported to be associated with nodal metastasis in oral squamous cell cancer (44). EMPI overexpression has also been established to be associated with poor OS in pediatric leukemia (17).

However, some studies have yielded different results. Lai et al (45), demonstrated that EMPl expression levels were higher in non-small-cell lung cancer compared with those in the benign control group. When a recombinant adenovirus overexpressing EMPI was constructed and virus-infected PC9 cells were transplanted into nude mice, the growth of the transplanted tumors could be observed. Another study by Zhang et al (46), demonstrated that EMPI was upregulated in human gliomas, and that EMPI expression was significantly increased in patients with World Health Organization tumor grade III-IV compared with grade I-II.

The results of the present study demonstrated that EMPI expression was downregulated in BLCA compared with that in normal tissues, but patients with low EMPl expression exhibited an improved OS rate compared with those in the high expression group. These conflicting results may be caused by the function of EMPI. Previous studies have demonstrated that EMP1 serves an important role in cell differentiation $(35,47,48)$ and proliferation $(34,49)$; thus, $E M P 1$ promotes cell differentiation, whereas tumor cells are characterized by de-differentiation. Low degree of tumor cell differentiation leads to low expression of EMPI. In addition, EMPI is a direct or indirect target gene of the classical proto-oncogene $c-m y c$, which serves a role in promoting cell proliferation (34). The results of the present study also demonstrated that in patients with high EMPI expression, the prognosis of BLCA was poor. This result was contrary to that of Peter et al (33), whose findings suggested that low expression of EMPI was associated with an increased risk of urothelial cancer-specific mortality. These differences may be due to the histological differences among the tumors, due to the differences in the internal and external environments of the tumor cells, and even due to the differences in the methods of data collection and analysis.

There is relatively little information about the signaling pathways associated with EMPI-mediated biological processes. Silencing experiments in the T-precursor ALL and B-ALL cell lines have indicated that EMPI may signal through the Src kinase family (17). Wang et al (50), transfected EMP1 into the esophageal cancer cell line EC9706 and reported that EMPI inhibited the proliferation of esophageal cancer cells, arrest the tumor cells in the S phase of the cell cycle or prolong the G1 phase. However, other study suggested that the EMP1 gene serves a role in promoting cell proliferation as a target gene of the proto-oncogene c-myc (19). EMPI is highly expressed with $c-m y c$ in active embryonic stem cells, but the expression gradually decreases as the embryo differentiates and matures (51). Currently, the mechanism of EMP1 in cell proliferation and apoptosis is not clear, but it is worth affirming that $E M P I$ exerts its effects mainly by regulating signal transduction between cells or between cells 
and the extracellular matrix (52). Ramnarain et al (21), have demonstrated that mutation in the EGFR gene leads to the activation of a series of downstream signals, including EMPI, as a result of which patients harboring the mutated EGFR are more likely to develop glioblastoma compared with those with wild-type EGFR. Durgan et al (53), have suggested that $E M P 1$, as an important transcriptional target in the Ras/mitogen-activated protein kinase pathway of bronchial epithelial cells, participates in the tight junction between cells and serves an important role in tracheal morphogenesis; its deletion may be associated to lung tumors. Lai et al (45), have reported that high expression of $E M P I$ leads to the occurrence and development of non-small-cell lung cancer by activating the PI3K/AKT pathway.

A number of previous studies have stated that members of the EMP family affect the integrin heterodimer repertoire on the plasma membrane, and modulation of the expression or localization of EMP proteins may alter the surface repertoire of molecules (54-56). The surface molecular repertoire, including major histocompatibility complex 1 proteins, integrins and other immunoglobulin superfamily members such as CD54 and glycosylphosphatidyl-inositol-linked proteins may be altered as the expression of EMP2 changes (57). These results suggest that members of the EMP family may influence the development of cancer cells via the tumor immune microenvironment and ultimately affect the prognosis of patients. However, there is lack of research on the association between $E M P 1$ and different immune cell infiltration in BLCA.

Based on previous studies, the present study further analyzed the correlation between $E M P I$ and the infiltration of various immune cells.

The results of the present study suggested that macrophage infiltration was an independent prognostic factor in BLCA, which was consistent with previous studies that have demonstrated significant associations between tumor-associated macrophage infiltration and shorter survival of patients with bladder cancer $(10,58,59)$. A number of studies have reported that a high neutrophil-lymphocyte ratio is a negative predictor of bladder cancer (60-63). In addition, neutrophil infiltration is significantly associated with poor prognosis of bladder cancer $(59,64)$. High $C D 4^{+}$T-cell density has been identified to be associated with poor prognosis in patients with bladder cancer $(65,66)$, and a high level of mature tumor-infiltrating DCs predicts progression to muscle invasion in bladder cancer (58). In the present study, EMPI expression was positively correlated with macrophage, neutrophil, $\mathrm{CD} 4^{+}$cell and DC infiltration, and negatively correlated with B lymphocyte infiltration, indicating that EMPI expression may be a negative regulator of tumor immunity. These results were consistent with previous studies of immune cell infiltration.

The correlation between EMPI expression and the enrichment of neutrophils and macrophages was further confirmed in the TISIDB in the present study. EMPI also exhibited a significant positive correlation with the enrichment of immune cells such as CD4, CD8, DCs, NK and NKT cells, which suggested that EMPI may aggravate the prognosis of patients by affecting the level of infiltration of specific immune cells. In addition, Treg and MDSC cells are considered to be suppressors of antitumor immune responses, and their enrichment is associated with poor patient outcomes in cancer (8,67-70). However, the results of B cell enrichment in TIMER and TISIBD in the present study were not consistent, reflecting the different algorithms used for the two immune scores. Although the mechanism of EMPI in tumor immunology is not fully understood, the correlations between $E M P 1$ expression and immune cell infiltration implicated the role of EMPI in regulating tumor immunology in BLCA.

Recent studies have provided possible mechanisms that may explain the association between EMP1 expression and inflammation. Wang et al (71), have demonstrated that low microRNA-31 expression in mesenchymal stem cells in patients with psoriasis causes an increase in the expression of $E M P I$, which in turn facilitates $\mathrm{T}$ lymphocyte activation. A study by Pan et al (72) has indicated that EMPl is activated by zinc finger protein 750 and regulates signaling pathways associated with proliferation and inflammation in CAL-27 cells.

To further elucidate the possible mechanism of EMPI expression in immunity, the present study speculated its possible function by assessing co-expression with previously reported gene markers. Co-expression of CCL-2, CD68, IL10 of TAMs, PTGS2, IRF5 of M1 phenotype, CD163, VSIG4 and $M S 4 A 4 A$ of the M2 phenotype with $E M P 1$ suggested that $E M P 1$ may regulate macrophage polarization. DC markers (e.g., HLA-DPB1, HLA-DRA, BDCA-1, and ITGAX) also exhibited a significant correlation with $E M P I$ expression, indicating an association between DC penetration and EMPI. Together, DC and T cells can secrete IL-12 and IL-18 to activate T cell proliferation, induce CTL production, and trigger a Th1-type immune response, which are conducive to tumor clearance (73). Treg markers (FOXP3, CCR8, TGFBI) were significantly co-expressed with EMPI. FOXP3 serves an essential role in maintaining homeostasis of the immune system by facilitating the acquisition of full suppressive function and stability of the Treg lineage, and by directly modulating the expansion and function of conventional $\mathrm{T}$ cells (74). These results indicated that $E M P 1$ expression may serve a complex role in the immune regulation network.

Checkpoint inhibitors are monoclonal antibodies that block inhibitory checkpoint antigens and repress the stimulation of $\mathrm{T}$ cells, exhibiting anticancer effects $(75,76)$. Upon chronic stimulation by tumor antigens, tumor-infiltrating $\mathrm{T}$ cells lose their effector functions and their ability to kill tumor cells, accompanied by a progressive increase in the diversity and number of inhibitory receptors expressed on them, including CD274, PDCD1LG2, HAVCR2, CTLA4, LAG3, PDCDI and TIGIT (75-82). Therefore, genes that were associated with immune checkpoints were selected for analysis in the present study.

The results of the present study revealed significant co-expression between EMPI and the genes reported to be associated with immune checkpoints, suggesting that EMPI may serve a role in BLCA by affecting these immune checkpoints. Previous results have suggested a positive correlation between $E M P I$ and Treg, which inhibits the immune response of other immune cells. These results suggest that EMPI may restore the function of immune cells by inhibiting immune checkpoints. Blocking antibodies against EMPI may be a promising treatment strategy for patients with BLCA.

The present study had certain limitations. Further research, including deep sequencing, is needed to elucidate the full spectrum of variability and any functional variants of $E M P I$ 
in BLCA. It is also necessary to further explore the specific molecular mechanism of EMPI in bladder cancer cells.

In conclusion, the results of the present study demonstrated that variations in the EMPl expression levels were associated with the prognosis of patients with BLCA. High EMPI expression was associated with a poor OS rate. In addition, these results revealed that the extent of immune cell infiltration and the diversity of immune marker expression were associated with EMP1 expression in BLCA. Therefore, the results of the present study may provide insights into the potential function of EMPI in tumor immunology and its potential as a cancer biomarker.

\section{Acknowledgements}

No applicable.

\section{Funding}

The current study was supported by the Shenzhen Healthcare Research Project (grant no. SZLY2018022).

\section{Availability of data and materials}

All data generated or analyzed during this study are included in this published article.

\section{Authors' contributions}

HY designed the research and reviewed the manuscript. BL analyzed the data and prepared the original draft. TZ and XY performed statistical calculation and experiments. All authors read and approved the final manuscript.

\section{Ethics approval and consent to participate}

This study was approved by the Ethics Committee of Peking university Shenzhen hospital (Shenzhen, China). Signed informed consents were obtained from the patients and/or guardians.

\section{Patient consent for publication}

No applicable.

\section{Competing interests}

The authors declare that they have no competing interests.

\section{References}

1. Bray F, Ferlay J, Soerjomataram I, Siegel RL, Torre LA and Jemal A: Global Cancer Statistics 2018: GLOBOCAN estimates of incidence and mortality worldwide for 36 cancers in 185 countries. CA Cancer J Clin 68: 394-424, 2018.

2. Burger M, Catto JW, Dalbagni G, Grossman HB, Herr H, Karakiewicz P, Kassouf W, Kiemeney LA, La Vecchia C, Shariat S, et al: Epidemiology and risk factors of urothelial bladder cancer. Eur Urol 63: 234-241, 2013.

3. Cumberbatch MGK, Jubber I, Black PC, Esperto F, Figueroa JD, Kamat AM, Kiemeney L, Lotan Y, Pang K, Silverman DT, et al: Epidemiology of bladder cancer: A systematic review and contemporary update of risk factors in 2018. Eur Urol 74: 784-795, 2018.
4. Obara W, Eto M, Mimata H, Kohri K, Mitsuhata N, Miura I, Shuin T, Miki T, Koie T, Fujimoto H, et al: A phase I/II study of cancer peptide vaccine S-288310 in patients with advanced urothelial carcinoma of the bladder. Ann Oncol 28: 798-803, 2017.

5. Lavoie JM, Bidnur S, Black PC and Eigl BJ: Expanding immunotherapy options for bladder cancer: commentary on: Pembrolizumab as second-line therapy for advanced urothelial carcinoma. Urology 106: 1-2, 2017.

6. Hamilou Z, Lavaud P and Loriot Y: Atezolizumab in urothelial bladder carcinoma. Future Oncol 14: 331-341, 2018.

7. Kamat AM, Bellmunt J, Galsky MD, Konety BR, Lamm DL, Langham D, Lee CT, Milowsky MI, O'Donnell MA, O'Donnell PH, et al: Society for Immunotherapy of Cancer consensus statement on immunotherapy for the treatment of bladder carcinoma. J Immunother Cancer 5: 68, 2017.

8. Liu YN, Zhang H, Zhang L, Cai TT, Huang DJ, He J, Ni HH, Zhou FJ, Zhang XS and Li J: Sphingosine 1 phosphate receptor-1 (S1P1) promotes tumor-associated regulatory T cell expansion: Leading to poor survival in bladder cancer. Cell Death Dis 10: $50,2019$.

9. Mukherjee N, Ji N, Hurez V, Curiel TJ, Montgomery MO, Braun AJ, Nicolas M, Aguilera M, Kaushik D, Liu Q, et al: Intratumoral CD56bright natural killer cells are associated with improved survival in bladder cancer. Oncotarget 9: 36492-36502, 2018.

10. Sjödahl G, Lövgren K, Lauss M, Chebil G, Patschan O, Gudjonsson S, Månsson $\mathrm{W}$, Fernö M, Leandersson K, Lindgren D, et al: Infiltration of CD3+ and CD68+ cells in bladder cancer is subtype specific and affects the outcome of patients with muscle-invasive tumors. Urol Oncol 32: 791-797, 2014.

11. Wang B, Xie S, Bi J, Liu Z, Zeng H, Huang H, Xue M, He Z, Yang M, Yu H, et al: Elevated pre-existing lymphocytic infiltrates in tumour stroma predict poor prognosis in resectable urothelial carcinoma of the bladder. Histopathology 75: 354-364, 2019.

12. Sun GG, Lu YF, Fu ZZ, Cheng YJ and Hu WN: EMP1 inhibits nasopharyngeal cancer cell growth and metastasis through induction apoptosis and angiogenesis. Tumour Biol 35: 3185-3193, 2014

13. Sun G, Zhao G, Lu Y, Wang Y and Yang C: Association of EMP1 with gastric carcinoma invasion, survival and prognosis. Int J Oncol 45: 1091-1098, 2014.

14. Sun GG, Wang YD, Cui DW, Cheng YJ and Hu WN: Epithelial membrane protein 1 negatively regulates cell growth and metastasis in colorectal carcinoma. World J Gastroenterol 20: 4001-4010, 2014.

15. Sun GG, Wang YD, Lu YF and Hu WN: EMP1, a member of a new family of antiproliferative genes in breast carcinoma. Tumour Biol 35: 3347-3354, 2014.

16. Sun GG, Wang YD, Cui DW, Cheng YJ and Hu WN: EMP1 regulates caspase-9 and VEGFC expression and suppresses prostate cancer cell proliferation and invasion. Tumour Biol 35: 3455-3462, 2014.

17. Ariës IM, Jerchel IS, van den Dungen RE, van den Berk LC, Boer JM, Horstmann MA, Escherich G, Pieters R and den Boer ML: EMP1, a novel poor prognostic factor in pediatric leukemia regulates prednisolone resistance, cell proliferation, migration and adhesion. Leukemia 28: 1828-1837, 2014.

18. Jain A, Tindell CA, Laux I, Hunter JB, Curran J, Galkin A, Afar DE, Aronson N, Shak S, Natale RB, et al: Epithelial membrane protein-1 is a biomarker of gefitinib resistance. Proc Natl Acad Sci USA 102: 11858-11863, 2005.

19. Ben-Porath I and Benvenisty $\mathrm{N}$ : Characterization of a tumor-associated gene, a member of a novel family of genes encoding membrane glycoproteins. Gene 183: 69-75, 1996.

20. Li YQ, Xue T, Wang L, Xu ZC, Xi ZQ, Yuan J, Wang XF, Chen YM, Zhang M and Yao L: Up-regulation of epithelial membrane protein-1 in the temporal neocortex of patients with intractable epilepsy. Neurochem Res 34: 1594-1602, 2009.

21. Ramnarain DB, Park S, Lee DY, Hatanpaa KJ, Scoggin SO, Otu H, Libermann TA, Raisanen JM, Ashfaq R, Wong ET, et al: Differential gene expression analysis reveals generation of an autocrine loop by a mutant epidermal growth factor receptor in glioma cells. Cancer Res 66: 867-874, 2006.

22. De Marco C, Laudanna C, Rinaldo N, Oliveira DM, Ravo M, Weisz A, Ceccarelli M, Caira E, Rizzuto A, Zoppoli P, et al: Specific gene expression signatures induced by the multiple oncogenic alterations that occur within the PTEN/PI3K/AKT pathway in lung cancer. PLoS One 12: e0178865, 2017. 
23. Wang YW, Li WM, Wu WJ, Chai CY, Chang TY, Sun Y, Cheng CJ, Shiue YL, Su SJ, Cheng HL, et al: Epithelial membrane protein 2 is a prognostic indictor for patients with urothelial carcinoma of the upper urinary tract. Am J Pathol 183: 709-719, 2013.

24. Humphrey PA, Moch H, Cubilla AL, Ulbright TM and Reuter VE: The 2016 WHO Classification of Tumours of the Urinary System and Male Genital Organs-Part B: Prostate and bladder tumours. Eur Urol 70: 106-119, 2016

25. Demirag GG, Kefeli M, Kemal Y and Yucel I: Epithelial membrane protein 1 expression in ovarian serous tumors. Oncol Lett 11: 2140-2144, 2016.

26. Li B and Dewey CN: RSEM: Accurate transcript quantification from RNA-Seq data with or without a reference genome. BMC Bioinformatics 12: 323, 2011.

27. Team R: Core. A language and environment for statistical computing. R Foundation for Statistical Computing, 2014.

28. Yoshihara K, Shahmoradgoli M, Martínez E, Vegesna R, Kim H, Torres-Garcia W, Treviño V, Shen H, Laird PW Levine DA, et al: Inferring tumour purity and stromal and immune cell admixture from expression data. Nat Commun 4 $2612,2013$.

29. Nagy Á, Lánczky A, Menyhárt O and Győrffy B: Validation of miRNA prognostic power in hepatocellular carcinoma using expression data of independent datasets. Sci Rep 8: 9227, 2018

30. Ru B, Wong CN, Tong Y, Zhong JY, Zhong SSW, Wu WC, Chu KC, Wong CY, Lau CY, Chen I, et al: TISIDB: An integrated repository portal for tumor-immune system interactions. Bioinformatics 35: 4200-4202, 2019.

31. Gao J, Aksoy BA, Dogrusoz U, Dresdner G, Gross B, Sumer SO, Sun Y, Jacobsen A, Sinha R, Larsson E, et al: Integrative analysis of complex cancer genomics and clinical profiles using the cBioPortal. Sci Signal 6: pl1, 2013.

32. Cerami E, Gao J, Dogrusoz U, Gross BE, Sumer SO, Aksoy BA Jacobsen A, Byrne CJ, Heuer ML, Larsson E, et al: The cBio cancer genomics portal: An open platform for exploring multidimensional cancer genomics data. Cancer Discov 2: 401-404, 2012.

33. Peter S, Borkowska E, Drayton RM, Rakhit CP, Noon A Chen W and Catoo JW: Identification of differentially expressed long noncoding RNAs in bladder cancer. Clin Cancer Res 20: 5311-21, 2014

34. Ben-Porath I, Kozak CA and Benvenisty N: Chromosomal mapping of Tmp (Emp1), Xmp (Emp2), and Ymp (Emp3), genes encoding membrane proteins related to Pmp22. Genomics 49: 443-447, 1998

35. Chen Y, Medvedev A, Ruzanov P, Marvin KW and Jetten AM: cDNA cloning, genomic structure, and chromosome mapping of the human epithelial membrane protein CL-20 gene (EMP1), a member of the PMP22 family. Genomics 41: 40-48, 1997.

36. Ahmat Amin MKB, Shimizu A and Ogita H: The pivotal roles of the epithelial membrane protein family in cancer invasiveness and metastasis. Cancers (Basel) 11: 11, 2019.

37. Da Y and Jia J: Study of antibodies to PMP22, IL-6 and TNF-alpha concentrations in serum in a CMTX1 family. Neurosci Lett 424: 73-77, 2007.

38. Gabriel CM, Gregson NA and Hughes RA: Anti-PMP22 antibodies in patients with inflammatory neuropathy. J Neuroimmunol 104 : $139-146,2000$

39. Kornberg LJ, Villaret D, Popp M, Lui L, McLaren R, Brown H, Cohen D, Yun J and McFadden M: Gene expression profiling in squamous cell carcinoma of the oral cavity shows abnormalities in several signaling pathways. Laryngoscope 115: 690-698, 2005

40. Kuriakose MA, Chen WT, He ZM, Sikora AG, Zhang P, Zhang ZY, Qiu WL, Hsu DF, McMunn-Coffran C, Brown SM, et al: Selection and validation of differentially expressed genes in head and neck cancer. Cell Mol Life Sci 61: 1372-1383, 2004.

41. Hippo Y, Yashiro M, Ishii M, Taniguchi H, Tsutsumi S, Hirakawa K, Kodama T and Aburatani H: Differential gene expression profiles of scirrhous gastric cancer cells with high metastatic potential to peritoneum or lymph nodes. Cancer Res 61: 889-895, 2001.

42. Wei Q, Li M, Fu X, Tang R, Na Y, Jiang M and Li Y: Global analysis of differentially expressed genes in androgen-independent prostate cancer. Prostate Cancer Prostatic Dis 10: 167-174, 2007.

43. Arslan AA, Gold LI, Mittal K, Suen TC, Belitskaya-Levy I, Tang MS and Toniolo P: Gene expression studies provide clues to the pathogenesis of uterine leiomyoma: New evidence and a systematic review. Hum Reprod 20: 852-863, 2005.

44. Zhang J, Cao W, Xu Q and Chen WT: The expression of EMP1 is downregulated in oral squamous cell carcinoma and possibly associated with tumour metastasis. J Clin Pathol 64: 25-29, 2011.
45. Lai S, Wang G, Cao X, Li Z, Hu J and Wang J: EMP-1 promotes tumorigenesis of NSCLC through PI3K/AKT pathway. J Huazhong Univ Sci Technolog Med Sci 32: 834-838, 2012

46. Zhang Ht: Lu YcandHe J. Expression of epithelial membrane protein 1 in human gliomas and its clinical implications. Zhongguo Zhongliu Shengwu Zhiliao Zazhi 14: 466-470, 2007.

47. Turashvili G, Bouchal J, Baumforth K, Wei W, Dziechciarkova M, Ehrmann J, Klein J, Fridman E, Skarda J, Srovnal J, et al: Novel markers for differentiation of lobular and ductal invasive breast carcinomas by laser microdissection and microarray analysis. BMC Cancer 7: 55, 2007.

48. Mackay A, Jones C, Dexter T, Silva RL, Bulmer K, Jones A, Simpson P, Harris RA, Jat PS, Neville AM, et al: cDNA microarray analysis of genes associated with ERBB2 (HER2/neu) overexpression in human mammary luminal epithelial cells. Oncogene 22: 2680-2688, 2003.

49. Lobsiger CS, Magyar JP, Taylor V, Wulf P, Welcher AA, Program AE and Suter U: Identification and characterization of a cDNA and the structural gene encoding the mouse epithelial membrane protein-1. Genomics 36: 379-387, 1996.

50. Wang HT, Kong JP, Ding F, Wang XQ, Wang MR, Liu LX, Wu M and Liu ZH: Analysis of gene expression profile induced by EMP-1 in esophageal cancer cells using cDNA Microarray. World J Gastroenterol 9: 392-398, 2003.

51. Ruegg CL, Wu HY, Fagnoni FF, Engleman EG and Laus R: $\mathrm{B} 4 \mathrm{~B}$, a novel growth-arrest gene, is expressed by a subset of progenitor/pre-B lymphocytes negative for cytoplasmic mu-chain. J Immunol 157: 72-80, 1996.

52. Wang YW, Cheng HL, Ding YR, Chou LH and Chow NH: EMP1, EMP 2, and EMP3 as novel therapeutic targets in human cancer. Biochim Biophys Acta Rev Cancer 1868: 199-211, 2017.

53. Durgan J, Tao G, Walters MS, Florey O, Schmidt A, Arbelaez V, Rosen N, Crystal RG and Hall A: SOS1 and Ras regulate epithelial tight junction formation in the human airway through EMP1. EMBO Rep 16: 87-96, 2015.

54. Morales SA, Telander DG, Mareninov S, Nagy A, Wadehra M, Braun $J$ and Gordon LK: Anti-EMP2 diabody blocks epithelial membrane protein 2 (EMP2) and FAK mediated collagen gel contraction in ARPE-19 cells. Exp Eye Res 102: 10-16, 2012.

55. Wadehra M, Forbes A, Pushkarna N, Goodglick L, Gordon LK, Williams CJ and Braun J: Epithelial membrane protein-2 regulates surface expression of alphavbeta3 integrin in the endometrium. Dev Biol 287: 336-345, 2005.

56. Morales SA, Mareninov S, Wadehra M, Zhang L, Goodglick L, Braun $\mathrm{J}$ and Gordon LK: FAK activation and the role of epithelial membrane protein 2 (EMP2) in collagen gel contraction. Invest Ophthalmol Vis Sci 50: 462-469, 2009.

57. Wadehra M, Goodglick L and Braun J: The tetraspan protein EMP2 modulates the surface expression of caveolins and glycosylphosphatidyl inositol-linked proteins. Mol Biol Cell 15: 2073-2083, 2004.

58. Ayari C, LaRue H, Hovington H, Caron A, Bergeron A, Têtu B, Fradet V and Fradet Y: High level of mature tumor-infiltrating dendritic cells predicts progression to muscle invasion in bladder cancer. Hum Pathol 44: 1630-1637, 2013.

59. Pichler R, Fritz J, Zavadil C, Schäfer G, Culig Z and Brunner A Tumor-infiltrating immune cell subpopulations influence the oncologic outcome after intravesical Bacillus Calmette-Guérin therapy in bladder cancer. Oncotarget 7: 39916-39930, 2016.

60. Kawahara T, Furuya K, Nakamura M, Sakamaki K, Osaka K, Ito H, Ito Y,Izumi K, Ohtake S, Miyoshi Y, et al: Neutrophil-to-lymphocyte ratio is a prognostic marker in bladder cancer patients after radical cystectomy. BMC Cancer 16: 185, 2016.

61. Peng D, Gong YQ, Hao H, He ZS, Li XS, Zhang CJ and Zhou LQ: Preoperative prognostic nutritional index is a significant predictor of survival with bladder cancer after radical cystectomy: A retrospective study. BMC Cancer 17: 391, 2017.

62. Hamilton-Reeves JM, Bechtel MD, Hand LK, Schleper A, Yankee TM, Chalise P, Lee EK, Mirza M, Wyre H, Griffin $\mathrm{J}$, et al: Effects of immunonutrition for cystectomy on immune response and infection rates: A pilot randomized controlled clinical trial. Eur Urol 69: 389-392, 2016.

63. Demirer $Z$ and Uslu AU: Predictive value of neutrophil-lymphocyte ratio in non-muscle-invasive bladder cancer. Urol Oncol 34: 1-2, 2016.

64. Zhou L, Xu L, Chen L, Fu Q, Liu Z, Chang Y, Lin Z and Xu J: Tumor-infiltrating neutrophils predict benefit from adjuvant chemotherapy in patients with muscle invasive bladder cancer. OncoImmunology 6: e1293211, 2017. 
65. Zhang Q, Hao C, Cheng G, Wang L, Wang X, Li C, Qiu J and Ding K: High CD4+ T cell density is associated with poor prognosis in patients with non-muscle-invasive bladder cancer. Int J Clin Exp Pathol 8: 11510-11516, 2015.

66. Pfannstiel C, Strissel PL, Chiappinelli KB, Sikic D, Wach S, Wirtz RM, Wullweber A, Taubert H, Breyer J, Otto W, et al; BRIDGE Consortium, Germany; BRIDGE Consortium, Germany; BRIDGE Consortium, Germany; BRIDGE Consortium, Germany: The Tumor Immune Microenvironment Drives a Prognostic Relevance That Correlates with Bladder Cancer Subtypes. Cancer Immunol Res 7: 923-938, 2019.

67. Wu K, Tan MY, Jiang JT, Mu XY, Wang JR, Zhou WJ, Wang X, Li MQ, He YY and Liu ZH: Cisplatin inhibits the progression of bladder cancer by selectively depleting G-MDSCs: A novel chemoimmunomodulating strategy. Clin Immunol 193: 60-69, 2018.

68. Smith SG, Baltz JL, Koppolu BP, Ravindranathan S, Nguyen K and Zaharoff DA: Immunological mechanisms of intravesical chitosan/interleukin-12 immunotherapy against murine bladder cancer. OncoImmunology 6: e1259050, 2016.

69. Horn T, Laus J, Seitz AK, Maurer T, Schmid SC, Wolf P, Haller B, Winkler M, Retz M, Nawroth R, et al: The prognostic effect of tumour-infiltrating lymphocytic subpopulations in bladder cancer. World J Urol 34: 181-187, 2016.

70. Winerdal ME, Krantz D, Hartana CA, Zirakzadeh AA, Linton L, Bergman EA, Rosenblatt R, Vasko J, Alamdari F, Hansson J, et al: Urinary bladder cancer tregs suppress MMP2 and potentially regulate invasiveness. Cancer Immunol Res 6 : 528-538, 2018

71. Wang Q, Chang W, Yang X, Cheng Y, Zhao X, Zhou L, Li J, Li J and Zhang K: Levels of miR-31 and its target genes in dermal mesenchymal cells of patients with psoriasis. Int J Dermatol 58 198-204, 2019.

72. Pan L, Yang H, Tang W, Xu C, Chen S, Meng Z, Li K and Chen H: Pathway-focused PCR array profiling of CAL-27 cell with over-expressed ZNF750. Oncotarget 9: 566-575, 2017.

73. Wang Y, Chaudhri G, Jackson RJ and Karupiah G: IL-12p40 and IL-18 play pivotal roles in orchestrating the cell-mediated immune response to a poxvirus infection. J Immunol 183: 3324-3331, 2009.

74. Kehrmann J, Effenberg L, Wilk C, Schoemer D, Ngo Thi Phuong N, Adamczyk A, Pastille E, Scholtysik R, Klein-Hitpass L, Klopfleisch R, et al: Depletion of Foxp3+ regulatory $\mathrm{T}$ cells is accompanied by an increase in the relative abundance of Firmicutes in the murine gut microbiome. Immunology 159: 344-353, 2020.

75. Sperk M, Domselaar RV and Neogi U: Immune checkpoints as the immune system regulators and potential biomarkers in HIV-1 infection. Int J Mol Sci 19: 19, 2018.
76. Chan AW, Zhang Z, Chong CC, Tin EK, Chow C and Wong N: Genomic landscape of lymphoepithelioma-like hepatocellular carcinoma. J Pathol 249: 166-172, 2019.

77. Yoshikawa T, Nakatsugawa M, Suzuki S, Shirakawa H, Nobuoka D, Sakemura N, Motomura Y, Tanaka Y, Hayashi S and Nakatsura T: HLA-A2-restricted glypican-3 peptide-specific CTL clones induced by peptide vaccine show high avidity and antigen-specific killing activity against tumor cells. Cancer Sci 102: 918-925, 2011.

78. Germeau C, Ma W, Schiavetti F, Lurquin C, Henry E, Vigneron N, Brasseur F, Lethé B, De Plaen E, Velu T, et al: High frequency of antitumor $\mathrm{T}$ cells in the blood of melanoma patients before and after vaccination with tumor antigens. J Exp Med 201: 241-248, 2005.

79. Takashima Y, Kawaguchi A, Sato R, Yoshida K, Hayano A, Homma J, Fukai J, Iwadate Y, Kajiwara K, Ishizawa S, et al: Differential expression of individual transcript variants of PD-1 and PD-L2 genes on Th-1/Th-2 status is guaranteed for prognosis prediction in PCNSL. Sci Rep 9: 10004, 2019.

80. Zhou G, Sprengers D, Boor PPC, Doukas M, Schutz H, Mancham S, Pedroza-Gonzalez A, Polak WG, de Jonge J, Gaspersz M, et al: Antibodies against immune checkpoint molecules restore functions of tumor-infiltrating $\mathrm{T}$ cells in hepatocellular carcinomas. Gastroenterology 153: 1107-1119e10, 2017.

81. Kim JY, Lee E, Park K, Park WY, Jung HH, Ahn JS, Im YH and Park YH: Immune signature of metastatic breast cancer: Identifying predictive markers of immunotherapy response. Oncotarget 8: 47400-47411, 2017.

82. Flecken $T$, Schmidt N, Hild S, Gostick E, Drognitz O, Zeiser R, Schemmer P, Bruns H, Eiermann T, Price DA, et al: Immunodominance and functional alterations of tumor-associated antigen-specific CD8+ T-cell responses in hepatocellular carcinoma. Hepatology 59: 1415-1426, 2014.

This work is licensed under a Creative Commons Attribution-NonCommercial-NoDerivatives International (CC BY-NC-ND 4.0) License. 